Discussion Paper No. 06-094

\title{
Dynamic R\&D Incentives with Network Externalities
}

Daniel Cerquera

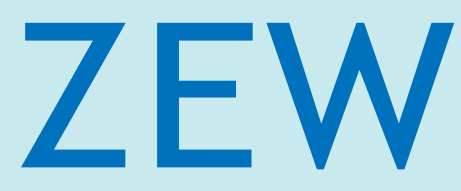

Zentrum für Europäische Wirtschaftsforschung $\mathrm{GmbH}$

Centre for European

Economic Research 


\title{
Discussion Paper No. 06-094 \\ Dynamic R\&D Incentives with Network Externalities
}

\author{
Daniel Cerquera
}

Download this ZEW Discussion Paper from our ftp server:

ftp://ftp.zew.de/pub/zew-docs/dp/dp06094.pdf

Die Discussion Papers dienen einer möglichst schnellen Verbreitung von neueren Forschungsarbeiten des ZEW. Die Beiträge liegen in alleiniger Verantwortung der Autoren und stellen nicht notwendigerweise die Meinung des ZEW dar.

Discussion Papers are intended to make results of ZEW research promptly available to other economists in order to encourage discussion and suggestions for revisions. The authors are solely responsible for the contents which do not necessarily represent the opinion of the ZEW. 


\section{Non-technical summary}

An industry exhibits network externalities when the benefit that consumers enjoy from purchasing one or several of its goods depends on the number of other consumers that use the same and/or compatible products (e.g. software, operating systems, telecommunications, consumer electronics, etc.). These industries exhibit two main characteristics that distinguish them from more conventional markets. First, they exhibit rapid technological progress and competition is focused on investments in R\&D in order to develop innovations that will provide market leadership (e.g interactive TV, video formats, digital imaging, etc.). Second, although new firms enter the market, they are characterized by highly concentrated market structures (e.g. operating systems, audio formats, video games, etc.).

This paper develops a fully dynamic duopoly model of quality competition in the presence of network externalities and endogenous and uncertain R\&D investments. It numerically investigates the effect of network externalities on the incentives to invest in $\mathrm{R} \& \mathrm{D}$, the efficiency of those investments in comparison with the social optimum and the potential role of competition policy. Moreover, given that industry evolution is driven by innovations that are dynamic in nature, we analyze the impact of network externalities on the short and long-run evolution of the industry. Finally, and due to the considerable short-run market power that these industries tend to exhibit, the impact of competition policy on the dynamic evolution of the industry is analyzed and some policy prescriptions that can increase consumers' welfare are proposed.

The paper shows three main results. First, network externalities positively affect the incentives to invest in R\&D. In the model, competition resembles a preemption race (i.e. winner-takes-all) and installed bases (i.e. network sizes) increase the prize that can be won by a successful innovator. As a consequence, market performance tends to over-invest in $R \& D$ in comparison with the socially optimal amount. Second, network externalities have an important impact in the dynamic evolution of the industry. Although in the long-run a single firm dominates the market (i.e. wins the race), in the short-run competition is fierce and it is concentrated on firms with similar technologies. And third, policy measures that increase the level of competition (e.g. mandatory licensing) and prolong the fierce shortrun competition in the industry may have an important positive impact on consumers' welfare and on firms' R\&D incentives. 


\title{
Dynamic R\&D Incentives with Network Externalities
}

\author{
Daniel CERQUERA*
}

December 29, 2006

\begin{abstract}
This paper studies the incentives to undertake uncertain R\&D initiatives in a dynamic duopoly network industry. It is shown that network externalities positively affect the incentives to invest in $\mathrm{R} \& \mathrm{D}$. In the model, competition resembles a preemption race and, therefore, market performance implies an over-investment in $\mathrm{R} \& \mathrm{D}$ in comparison with the social optimum. Moreover, network externalities have an important impact in the dynamic evolution of the industry. Although in the long-run a single firm dominates the market (i.e. wins the race), short-run competition is very fierce and concentrated on neck-and-neck technological configurations. This short-run competition is fiercer and longer, the higher the level of network externalities. Policy measures that increase technological diffusion (i.e. mandatory licensing), increase the level of competition and/or prolong the short-run competition have an important positive impact on consumer welfare and on firms' R\&D incentives.
\end{abstract}

Keywords: Network externalities, Innovation, Imperfect Competition, Dynamic Games. JEL Classification: L13, D85, O31, C73.

\footnotetext{
*cerquera@zew.de. Centre for European Economic Research (ZEW), Mannheim, Germany. Research Group Information and Communication Technologies. I would like to thank Irene Bertschek, Jay P. Choi, Toker Doganoglu, Stefan Mittnik, Monika Schnitzer and Sven Rady for helpful comments and suggestions, as well as seminar participants at the University of Munich and the 2006 Econometric Society meetings in Vienna and Mexico City. Part of this research was completed at the Center for Information and Network Economics at the University of Munich. Generous financial support from Volkswagen Stiftung and the Munich Graduate School of Economics made this research possible. All errors are mine.
} 


\section{Introduction}

An industry exhibits network externalities when the benefit that consumers enjoy from purchasing one or several of its goods depends on the number of other consumers that use the same and/or compatible products. For the firms in those sectors (e.g. software, operating systems, telecommunications, consumer electronics, etc.), the presence of network externalities implies that the attractiveness of their products is a function of their quality-adjusted prices and the potential benefits attached to their expected network sizes (i.e. installed bases) $!^{1}$

Network industries exhibit several properties that do not only distinguish them from more conventional markets, but that decisively affect firms' strategies $2^{2}$ On the one hand, rapid technological progress is a common observation in many industries with network externalities $3^{3}$ In fact, competition in network industries centers around investments in intellectual property (i.e. R\&D) in order to develop and introduce drastic innovations that will confer market leadership $4^{4}$ On the other hand, and partially as a consequence of the strong technological competition, industries that exhibit network externalities tend to be characterized by a highly concentrated market structure (i.e. operating systems, audio formats, video games, etc.). This situation is reinforced by the role of consumers' expectations..$^{5}$

As a result of these two characteristics of network industries (i.e. rapid technological progress and market concentration), formal analyses on the evolution of these industries are particularly relevant for policy considerations. For instance, competition policy plays a key role as a mean to monitor such unavoidable market dominance (i.e. to limit undesirable market power) without hindering innovation incentives (i.e. to protect the benefits and rights of successful innovators).

\footnotetext{
${ }^{1}$ See Katz and Shapiro $(1985,1986)$ and Farrel and Saloner $(1985,1986)$ for seminal treatments, and Katz and Shapiro (1994) and Economides (1996) for surveys on network markets.

${ }^{2}$ See, for example, Gabel (1991), Besen and Farrell (1994), Katz and Shapiro (1994), Grindley (1995) and Shapiro and Varian (1999) for general analyses of the impact of network externalities on firms' strategies.

${ }^{3}$ Technological innovations allow rivalling firms to introduce new products like interactive TV, Digital Versatile Disk (DVD), and digital imaging. In nascent industries, extensive investments in R\&D are usually required to introduce new standards or dominant designs.

${ }^{4}$ Evans and Schmalensee (2001) argue that firms in network industries engage in competition "for the market", as opposed to static price/output competition "in the market".

${ }^{5}$ Due to the presence of network externalities, a network technology may dominate a market only because it is expected to do so. The initial success of the MS-DOS operating system is attributed not to any technical superiority, but to the fact that it was supported by IBM.
} 
This paper develops a fully dynamic duopoly model of quality competition in the presence of network externalities and endogenous and uncertain $R \& D$ investments. We investigate the effect of network externalities on the incentives to invest in $R \& D$, the efficiency of those investments in comparison with the social optimum and the potential role of competition policy. Moreover, given that industry evolution is driven by innovations that are dynamic in nature, we analyze the impact of network externalities on the short and long-run evolution of the industry. Finally, and due to the considerable short-run market power that these industries tend to exhibit, we also analyze the impact of competition policy on the dynamic evolution of the industry and propose some policy prescriptions that can increase consumers' welfare.

In spite of its relevance, the literature on investment processes, R\&D efforts and innovation initiatives in industries that exhibit network externalities is still in its early stage of development. The existing literature, in its great majority, takes the processes of R\&D as exogenously given and analyzes the conditions under which an innovation is adopted. Moreover, most of the work devoted to the analysis of investment decisions with network externalities considers situations where the entrant arrives with a (exogenously given) new technology, without considering a strategic response by the incumbent to the threat of entry. $!^{6}$

Some of the main results of this literature are: i) new technologies tend to be adopted too early and the successful entrant becomes an incumbent forever; ii) the structure of property rights (i.e. sponsorship) over a new technology affect decisively its potential for adoption; and iii) R\&D incentives play no major role in affecting consumers' expectations, and hence, consumers' choice. Kristiansen (1996) and Choi (1994) consider the case of endogenous investment in network industries using two-period models and analyze the riskiness associated to the $R \& D$ projects. Their results are focused on the divergence between private and social incentives to invest and show the role of network externalities in this divergence.

In this paper, our dynamic model of quality competition with network externalities adapts the Markov-perfect equilibrium framework presented in Ericson and Pakes (1995). We depart from the current literature on network industries by focusing our analysis on four main areas. First, we consider endogenous and uncertain R\&D efforts taking into

\footnotetext{
${ }^{6}$ See Farrell and Saloner (1985), Farrell and Saloner (1986), Katz and Shapiro (1986), Katz and Shapiro (1992), De Bijil and Goyal (1995), Shy (1996), Fudenberg and Tirole (2000), among others.
} 
account the way consumers form expectations. This allows us to analyze the incentives to innovate as a result of strategic interaction inside the industry, to explore the impact of network externalities on industry evolution and to compare our results with novel advances in the literature on innovation-led growth. Second, we embed our analysis in a fully dynamic framework. This implies that our results are independent of initial and/or end conditions, permitting us to determine the equilibrium market structure endogenously and to follow the industry through different time horizons. Third, we consider explicitly the impact on the short and long-run social efficiency of the R\&D incentives that drives the evolution of the network industry and the role of competition policy in this evolution. And fourth, we provide an assessment of the question whether competition policy should be cautious in dynamically competing industries, as has been suggested by some observers.

More specifically, we consider two firms, an established firm and a challenger, that compete each period with two incompatible technologies over an infinite horizon. To capture the role of the installed base, we assume overlapping generations of homogeneous consumers that live for two periods and make purchases (inelastically) only once when they arrive to the market. Thus, in each period the population consists of a "young" and an "old" generation of consumers.

The established firm in period $t$ is the firm that won competition in period $t-1$ ("young" consumers bought from it) and exhibits an installed base in period $t$ ("old" consumers cannot make another purchase). In addition, both firms offer a technology, whose quality can be improved through endogenous and uncertain R\&D efforts. At each $t$, a firm invests in order to develop, with positive probability, an improvement of its quality for period $t+1$. For simplicity, we assume that R\&D outcome is either a success or a failure and, if it is successful, it increments the value of the quality by a fixed amount.

Moreover, our flexible specification allows us to analyze the impact of the level of competition on industry performance. In our framework, the role of competition is captured by the (exogenous) probability that in a given period the relative quality of a network good is reduced. This situation can be interpreted as the role played by independent research facilities, universities, intellectual property law, etc. Therefore, our model captures the idea of quality competition in a market facing competitive pressure from within and outside the industry. Given that competition takes place each period depending on the level of quality of the good produced by the two firms, which in turn depends on the stochastic $R \& D$ processes, the drivers of industry evolution are the investment incen- 
tives of the competing firms. This setup allows us to compare our results with important existing work on the interplay between $R \& D$, innovation and the level of competition.

The model is solved in two steps. In the first step, the product market competition observed in each period is determined considering the expectation formation process. For any given quality state (i.e. quality levels of the two firms), the equilibrium prices and per-period profits are computed, allowing us to see the impact of network externalities on consumers' behavior. In the second step, given the outcome of the product market competition, the fully dynamic investment decision problem is stated and solved numerically using the methodology developed by Pakes and McGuire (1994). Equilibrium occurs when the two firms' expectations about their competitors strategies are consistent with their actual behavior.

We show three main results. First, network externalities affect positively the incentives to invest in $\mathrm{R} \& \mathrm{D}$. In our model, competition resembles a preemption race and installed bases increase the prize that can be won by a successful competitor. As a consequence, it is not surprising that market performance tends to over-invest in R\&D. Second, network externalities have an important impact in the dynamic evolution of the industry. Although in the long-run a single firm dominates the market (i.e. wins the race) and this outcome is socially optimal, in the short-run competition is stronger and it is concentrated on neckand-neck technological industry configurations. And third, policy measures that increase the level of competition and prolong the fierce short-run competition in the industry may have an important impact on consumers' welfare and on firms' R\&D incentives.

The paper is organized as follows. The next section presents the model. Section 3 presents the analysis of its equilibrium and the main results. Finally, section 4 concludes and discusses some areas of further research.

\section{The Model}

We present a model of duopoly competition in a market that exhibits network externalities. Time evolves discretely over an infinite horizon in order to avoid end effects. Both firms produce with identical marginal costs but potentially different qualities. Consumers are assumed to be homogeneous in an overlapping generations structure. 


\subsection{Supply Side and R\&D Process}

There are two firms in the industry producing network goods. Let $f \in F=\{0,1\}$ denote the identity of the firms, where 0 represents a firm that lacks an installed base and 1 represents the firm with an installed base.7 ${ }^{7}$ it is assumed that goods produced by different firms are mutually incompatible. That is, the size of the network associated with a given firm is equal to the number of users of the good produced by that firm. For simplicity it is assumed that marginal and fixed costs of production are equal to zero 8

At any period $t$, each firm exhibits a given quality embedded in the network good it produces. This quality level is indexed by $i$ and is independent of the network benefits that the good may provide. In order to simplify exposition, it is assumed that this level of quality is relative to an outside technology ${ }^{9}$ This assumption serves two purposes. First, it allows us to focus on a smaller set of possible qualities (i.e. relative qualities), and second, it provides an upper limit to the per-period profits of the firms. This latter condition is required for the existence of the equilibrium. For simplicity, it is further assumed that the outside technology does not provide any network benefit.

In our duopoly setup, we denote the competitor of firm $f$ and its quality level by $f_{-}$ and $j$, respectively. Therefore, a firm in the industry can be fully describe by its state $(i, j, f){ }^{10}$ We consider $i, j \in Q$, where $Q$ is the quality space and $f \in F$. We analyze the case of $Q=\{1,2, \ldots, M\}$. That is, there are $M$ possible (relative) quality levels that can be exhibited by a firm 11

Qualities evolve stochastically over time. This evolution depends on the firm's own costly R\&D efforts and on the developments of the outside technology and/or competitive environment. Specifically, firm f's own technology is improved with a probability that depends positively on its investments. Let $x_{f}$ denote the investment level on R\&D of firm $f$. We take the probability that firm $f$ improves its relative quality to be $\frac{x_{f}}{1+x_{f}}$. At the

\footnotetext{
${ }^{7}$ As will be explained below, the assumption of homogeneous consumers imply that in each period only one firm captures the entire market. This fact means that at the beginning of each period, one firm $(f=1)$ exhibit an installed base (i.e. captured the market the previous period), while the other firm has no such base $(f=0)$.

${ }^{8} \mathrm{~A}$ linear demand specification guarantees that this assumption is without loss of generality.

${ }^{9}$ The outside technology can be thought as a technology that is publicly available to firm $f$ and is produced in, for example, universities or research facilities. Formally, if the actual quality state of the technology produced by firm $f$ is $i^{*}$ and the outside technology available to this firm is $i^{\text {out }}$, then $i=i^{*}-i^{\text {out }}$.

${ }^{10}$ Note that $(i, j, f)$ actually describes the state of the industry because for every $(i, j, f)$ there is a corresponding $\left(j, i, f_{-}\right)$. This formulation will allow us to focus on a symmetric equilibrium.

${ }^{11}$ Note that the actual quality, the numerical value, is not defined yet.
} 
same time, $\delta$ denotes the probability that in each period the relative quality of firm $f$ is reduced. In our specification, the parameter $\delta$ can be interpreted as a measure of the level of competition faced by the industry. For instance, a higher value of $\delta$ could be associated with a more innovative independent research facilities or a higher degree of technology (knowledge) diffusion. Throughout the paper we identify this parameter with the level of competition 12

In the model, we assumed that relative qualities can only be improved (or reduced) one step each period. Hence, if $\mathrm{p}\left(i^{\prime} \mid i, x_{f}\right)$ denotes the probability that firm $f$ will have quality $i^{\prime}$ in $t+1$ given that it has quality $i$ and invests $x_{f}$ in $t$, we have,

$$
\mathrm{p}\left(i^{\prime} \mid i, x_{f}\right)= \begin{cases}\frac{x_{f}}{1+x_{f}} & \text { if } i^{\prime}=i+1 \\ \frac{1}{1+x_{f}} & \text { if } i^{\prime}=i\end{cases}
$$

if $i=1$,

$$
\mathrm{p}\left(i^{\prime} \mid i, x_{f}\right)= \begin{cases}\frac{(1-\delta) x_{f}}{1+x_{f}} & \text { if } i^{\prime}=i+1 \\ \frac{1-\delta+\delta x_{f}}{1+x_{f}} & \text { if } i^{\prime}=i \\ \frac{\delta}{1+x_{f}} & \text { if } i^{\prime}=i-1\end{cases}
$$

if $i=2, \ldots, M-1$, and

$$
\mathrm{p}\left(i^{\prime} \mid i, x_{f}\right)= \begin{cases}\frac{1-\delta+x_{f}}{1+x_{f}} & \text { if } i^{\prime}=i \\ \frac{\delta}{1+x_{f}} & \text { if } i^{\prime}=i-1\end{cases}
$$

if $i=M$. As can be seen, this formulation implies that a given level of quality evolves only one step within the state space (up, down or same position) from period to period. We now explain the details of the demand side.

\subsection{Demand Side and Expectation Formation Process}

At any period $t$, there are two overlapping generations of consumers that live for two periods. Each period a mass of 1 "young" consumers arrives into the market and join a mass of 1 "old" consumers, so the total population in each period is constant and equal

\footnotetext{
${ }^{12}$ Note that there are alternative interpretations for this parameter (e.g. quality depreciation). Below we present some conditions that support the interpretation we employ (i.e. level of competition).
} 
to 2. Consumers are assumed to be homogeneous with an inelastic demand for a single unit of the network goods offered by the firms. Upon arrival consumers observe the state of the industry (i.e. they observe $(i, j, f)$ and the corresponding $\left.\left(j, i, f_{-}\right)\right)$, investments, prices and, then, purchases take place. This process is explained below.

It is important to note that the assumption of homogeneous consumers imply that in each period only one firm captures the new generation of "young" consumers. Moreover, once a firm captures the market, it will exhibit an installed base in the next period because "old" consumers are locked-in. Therefore, at the beginning of each period there is one firm with an installed base (i.e. $f=1$ ) and one firm without it (i.e $f=0$ ).

Note that consumers buy a durable network good only once, which amounts to say that they exhibit prohibitively high switching cost, and therefore, they will be locked-in in the second period of their lives with the network good that they bought in their first period. In addition, note that before purchase takes place, consumers observe the investments undertaken by the competing firms, and thus, the strategic role of the investment decision is two-fold: i) to affect future quality; and ii) to influence directly consumers' expectations about the future installed base.

Importantly, in the presence of network externalities, a consumer decision depends on how other consumers are deciding. Therefore, consumers must form expectations about other consumers' behavior. In our setup, this expectation formation process has two dimensions. First, consumers arriving in the market in period $t$ must also care about how the other consumers also arriving in $t$ decide (i.e. my utility is higher, the more consumers in my own generation choose a compatible good). Second, given that consumers are locked-in when they are "old", consumers arriving in period $t$ must care about the choice made by the new generation of "young" consumers arriving in $t+1$ (i.e. my utility is higher, the more next generation consumers choose a compatible good). Moreover, consumers arriving in $t$ care about the choice of consumers arriving in $t+1$, which in turn care about the choice of consumers in $t+2$, and so on.

Therefore, in order to calculate demand, the process under which consumers form expectations must be determined in a way that is consistent with a dynamic equilibrium. We propose the following two-step expectation formation process. In the first step, concerning the behavior among individuals of the same generation, we assume that the consumers behave as "optimal coordinators". That is, consumers decide assuming that all 
their contemporaries are able to identify and coordinate on the Pareto-optimal choice ${ }^{13}$

In the second step, concerning the expectations on the behavior of future consumers, we assume that if in a given period the two competing goods exhibit the same quality, the good provided by the firm with an installed base is preferred. In the case of quality differences, the good with the higher quality is going to be favored. We assume that consumers in $t$ follow this rule and expect future consumers to follow it. As will be shown below, this rule is consistent with equilibrium behavior.

Now that the demand and supply side have been explained, and before we state formally the product market competition, as well as the firms' dynamic problem, we present the time structure. Specifically, at each period $t$ events develop as follows,

- (Relative) quality values are realized

- Firms invest to improve quality

- Prices are determined

- Consumers arrive and observe the current quality state, investments and prices

- Purchases take place

\subsection{Product Market Competition}

In each period, a firm finds itself in state $(i, j, f)$, where $i$ is the (relative to an outside good) quality state of the good it produces, $j$ is the quality state of the competing firm, and $f$ is the identity of the firm according to the installed base 14 As we explained before, consumers are homogeneous implying that only one firm captures the the entire market each period. We assume that firms are engaged in price (Bertrand) competition in the product market. Therefore, given our expectation formation process assumptions, we calculate the maximum utility that a consumer may enjoy from each of the two network goods, compare them and derive the corresponding equilibrium demands and prices.

Specifically, the benefit enjoyed by a generation of consumers arriving in the market in a given period and buying from the firm with the installed base $(f=1)$ is given by,

\footnotetext{
${ }^{13}$ See Katz and Shapiro (1986), and Farrell and Katz (2005).

${ }^{14}$ Again, note that a state $(i, j, f)$ implies that the competitor is in state $\left(j, i, f_{-}\right)$.
} 


$$
\begin{aligned}
u_{i}^{1}= & a_{i}+2 \omega+\beta\left[(1-\delta) a_{i}+\delta a_{i-1}\right. \\
& \left.+\omega\left(1+1 \cdot \mathrm{p}\left(i^{\prime}>j^{\prime} \mid i, j\right)+1 \cdot \mathrm{p}\left(i^{\prime}=j^{\prime} \mid i, j\right)\right)\right] .
\end{aligned}
$$

In this expression, the first two terms represent the utility enjoyed by the consumer in his first period when he is "young". In particular, $a_{i}$ represents the actual value of the quality level (given state $i$ ) and $2 \omega$ represents the network benefits. Recall that the quality values are relative to an outside option from competition outside the industry. Moreover, equation (1) implicitly says that the outside option is not a network good from a consumer's perspective ${ }^{15}$

Note that the expression presented in equation (1) is the utility derived from the consumption of the good provided by the firm with an installed base. Therefore, in this case the entire population would be consuming the good from firm $f=1$ and the network benefits is two times the valuation $\omega$ of those network benefits (i.e. $2 \omega$ ).

The third term corresponds to the utility derived in the second period when the consumer is "old", where $\beta$ is the discount factor. Given that the consumer is locked-in with his first period choice, in the second period he will enjoy the same good with a offered surplus that depends on the evolution of the relative quality. As mention before, this evolution is exogenous and is associated with the level of competition observed in the industry. That is, with probability $(1-\delta)$ the relative qualities do not change, while with probability $\delta$ relative qualities are reduced.

In terms of the network benefits enjoyed in his second period, it is clear that they depend on the choice made by the new generation. Therefore, according to our expectation rule (i.e. better quality firm captures the market or established firm does if qualities are equal), it can be presented as follows. The network benefits are weighted by the parameter $\omega$ that multiplies: i) the first term represents the network benefits derived by the fact that the consumer is locked-in in the second period; and ii) it will enjoy and extra generation if the technology adopted captures the market in the next period. This occurs with probability $\mathrm{p}\left(i^{\prime}>j^{\prime} \mid i, j\right)+\mathrm{p}\left(i^{\prime}=j^{\prime} \mid i, j\right)$, where $i$ is the quality exhibit by firm $f=1$ and

\footnotetext{
${ }^{15}$ This is the case, for example, of free software available on the internet. A consumer deciding to buy a software, may consider free software as a benchmark of quality without caring too much about the network benefits it provides.
} 
$j$ is the quality of its competitor in the current period. $i^{\prime}$ and $j^{\prime}$ represent the quality values in the next period for $f=1$ and the competitor $f=0$, respectively.

Analogously, we can describe the utility derived if the given generation of "young" consumers decides to purchase from the competing firm $f=0$. The interpretation follows the same lines as in the previous case.

$$
\begin{aligned}
u_{j}^{0}= & a_{j}+\omega+\beta\left[(1-\delta) a_{j}+\delta a_{j-1}\right. \\
& \left.+\omega\left(1+1 \cdot \mathrm{p}\left(i^{\prime}<j^{\prime} \mid i, j\right)+1 \cdot \mathrm{p}\left(i^{\prime}=j^{\prime} \mid i, j\right)\right)\right] .
\end{aligned}
$$

It can be shown that $i \geq j$ implies that the expression in equation (1) is greater than the one in equation (2). This result is important in order to work with an expectation rule that is dynamically consistent.

Given the homogeneity of the consumers, the demand function for each generation of "young" consumers is described as follows. Suppose $f$ represents the firm that exhibits the installed base and $i$ its quality, then, demand (the identity of the firm the "young" consumers buy from) as a function of the current state $(i, j, f)$ is given by,

$$
\mathrm{D}(i, j, f)= \begin{cases}f & \text { if } i \geq j \\ f_{-} & \text {if } i<j\end{cases}
$$

Under our assumption of Bertrand price competition, equilibrium prices are described as follows. Again, suppose $f$ represents the firm that exhibits the installed base and $i$ its quality,

$$
\mathrm{p}^{*}(i, j, f)= \begin{cases}\bar{a}_{i}+\omega+\beta\left[a_{i}-a_{j}+\omega\left(\mathrm{p}\left(i^{\prime}>j^{\prime}\right)-\mathrm{p}\left(i^{\prime}<j^{\prime}\right)\right)\right] & \text { if } i \geq j \\ \bar{a}_{j}-\omega+\beta\left[a_{j}-a_{i}+\omega\left(\mathrm{p}\left(j^{\prime}>i^{\prime}\right)-\mathrm{p}\left(j^{\prime}<i^{\prime}\right)\right)\right] & \text { if } i<j\end{cases}
$$

Where $\bar{a}_{i}=(1-\beta \delta)\left(a_{i}-a_{j}\right)+\beta \delta\left(a_{i-1}-a_{j-1}\right)$ and $\bar{a}_{j}=(1-\beta \delta)\left(a_{j}-a_{i}\right)+\beta \delta\left(a_{j-1}-a_{i-1}\right)$.

Given that each period the mass of new consumers is equal to 1 , the per-period profits $\pi(i, j, f)$ that result from product market competition equal the optimal Bertrand prices just presented (i.e. $\left.\mathrm{p}^{*}(i, j, f)=\pi(i, j, f)\right)$. Note that the determination of $\mathrm{p}^{*}(i, j, f)$ implicitly says that firms cannot price below zero. Given that marginal costs are equal 
to zero, this would be equivalent to negative mark-ups. However, the case of possible negative mark-ups is not considered. Even though it could be an interesting extension, negative mark-ups are associated with predatory pricing which is illegal and complicates greatly the model.

As can be seen from the price equilibrium expression, the profits obtained in period $t$ depend on the expected qualities that are going to be realized in period $t+1$, which in turn depends on the investment decisions by the two firms. Thus, in order to solve for the product market competition in $t$, we need to solve the dynamic problem that determines the distribution of $t+1$ qualities (i.e. equilibrium investments). In this way, we see how equilibrium prices are derived from dynamic incentives due to the role of investment decisions in affecting consumers choice. In order to do this, we need to state the dynamic problem using the following Bellman equations.

\subsection{Dynamic Setup}

Let $V(i, j, f)$ denote the expected net present value to firm $f$ when its quality level is given by $i$ and the quality level by its competitor is given by $j$. In what follows, we first characterize the value function $V(i, j, f)$ under the presumption that the firm behaves optimally. In a second step, we derive the policy function $x(i, j, f)$. Throughout we take the competitor firm's investment strategy as given.

The Bellman equation is,

$$
V(i, j, f)=\sup _{x \geq 0}\left[\pi(i, j, f)-c x+\beta\left[\sum_{i} \sum_{j} \sum_{f} V\left(i^{\prime}, j^{\prime}, f^{\prime}\right) p\left(f^{\prime}\right) p\left(j^{\prime}\right) p\left(i^{\prime}\right)\right]\right]
$$

where $0<\beta<1$ is the discount factor and $c$ represents the marginal cost of investment. The Bellman equation adds the firm's current cash flow $\pi(i, j, f)-c x$ and its discounted expected future cash flow.

Importantly, note that given our demand specification, a firm that captures the market today becomes, unambiguously, the established incumbent tomorrow. Therefore, for $f=$ $1, i \geq j$ implies $f^{\prime}=1$ and $f^{\prime}=0$, otherwise. Analogously, for $f=0, i>j$ implies $f^{\prime}=1$ and $f^{\prime}=0$, otherwise. This allows us to simplify the Bellman equations as follows, 


$$
V(i, j, 1)=\sup _{x \geq 0}\left[\pi(i, j, 1)-c x+\beta\left[\sum_{i} \sum_{j} V\left(i^{\prime}, j^{\prime}, 1\right) p\left(j^{\prime}\right) p\left(i^{\prime}\right)\right]\right],
$$

whenever $i \geq j$ (i.e. a firm with an installed base is able to maintain its dominant position).

$$
V(i, j, 1)=\sup _{x \geq 0}\left[\pi(i, j, 1)-c x+\beta\left[\sum_{i} \sum_{j} V\left(i^{\prime}, j^{\prime}, 0\right) p\left(j^{\prime}\right) p\left(i^{\prime}\right)\right]\right],
$$

if $i<j$ (i.e. the established firm loses its dominance).

$$
V(i, j, 0)=\sup _{x \geq 0}\left[\pi(i, j, 0)-c x+\beta\left[\sum_{i} \sum_{j} V\left(i^{\prime}, j^{\prime}, 1\right) p\left(j^{\prime}\right) p\left(i^{\prime}\right)\right]\right],
$$

if $i>j$ (i.e. the firm without the installed base captures the market). And finally,

$$
V(i, j, 0)=\sup _{x \geq 0}\left[\pi(i, j, 0)-c x+\beta\left[\sum_{i} \sum_{j} V\left(i^{\prime}, j^{\prime}, 0\right) p\left(j^{\prime}\right) p\left(i^{\prime}\right)\right]\right],
$$

if $i \leq j$ (i.e. the challenging firm keeps competing without an installed base).

Note that, for a given $i^{\prime}$ and $f^{\prime}$, we can define $W_{1}\left(i^{\prime}\right)=\sum_{j} V\left(i^{\prime}, j^{\prime}, 1\right) p\left(j^{\prime}\right)$ and $W_{0}\left(i^{\prime}\right)=$ $\sum_{j} V\left(i^{\prime}, j^{\prime}, 0\right) p\left(j^{\prime}\right)$ as the expected state of the competitor. Thus, the general expression for the Bellman equation can be written as,

$$
V(i, j, f)=\sup _{x \geq 0}\left[\pi(i, j, f)-c x+\beta\left[\sum_{i} W_{f^{\prime}}\left(i^{\prime}\right) p\left(i^{\prime}\right)\right]\right]
$$

where,

$$
f^{\prime}= \begin{cases}1 & \text { if } f=1 \text { and } i \geq j \\ 0 & \text { if } f=1 \text { and } i<j \\ 1 & \text { if } f=0 \text { and } i>j \\ 0 & \text { if } f=0 \text { and } i \leq j\end{cases}
$$

Note that $W_{f^{\prime}}\left(i^{\prime}\right)$ is the expectation over all possible future states calculated under the presumption that firm $f$ invests $x(i, j, f)$, and its competitor, firm $f_{-}$, invests $x\left(j, i, f_{-}\right)$. In addition, $W_{f^{\prime}}\left(i^{\prime}\right)$ is all that firm $f$ needs to know in order to compete in the market. 


\subsection{Investment Strategies}

The first-order condition (FOC) for an interior solution is,

$$
\frac{\partial \pi(i, j, f)}{\partial x_{f}}-c+\beta \sum_{i} W_{f^{\prime}}\left(i^{\prime}\right) \frac{\partial p\left(i^{\prime}\right)}{\partial x_{f}}=0 .
$$

for,

$$
f^{\prime}= \begin{cases}1 & \text { if } f=1 \text { and } i \geq j \\ 0 & \text { if } f=1 \text { and } i<j \\ 1 & \text { if } f=0 \text { and } i>j \\ 0 & \text { if } f=0 \text { and } i \leq j\end{cases}
$$

Consider $i=2$ as a general case. It can be shown that the second-order condition is satisfied whenever a solution to equation (4) exist. Moreover, the equilibrium investment level is the maximum between zero and the value of $x$ that solves equation (4).

\subsection{Equilibrium}

As we explained before, given that each firm, and therefore the industry, can be totally described according to the state $(i, j, f)$, this allows us to focus attention to symmetric Markov-perfect equilibria (MPE) as defined by Maskin and Tirole (1988). This concept selects those subgame-perfect equilibria where actions are a function only of pay-off relevant state variables, and thus eliminates many of the vast multiplicity of subgame-perfect equilibria that would normally exist in this type of model. Firms maximize their expected discounted value of profits conditional on their expectations of the evolution of competition. Equilibrium occurs when the two firms' expectations are consistent with the process generated by the optimal policies of their competitors. ${ }^{16}$

Proof that equilibrium exists has been shown in the literature ${ }^{17}$ The proof is omitted both because it would replicate previous work and because such a proof would be redundant given that our approach in this paper is to solve numerically for equilibrium once the parameters of the model are defined. In the event that the numerical algorithm

\footnotetext{
${ }^{16}$ For a detailed review of this methodology, see Doraszelski and Pakes (2006).

${ }^{17}$ Given that the model does not consider explicitly the entry and/or exit decisions, existence is guaranteed. See Doraszelski and Satterthwaite (2005).
} 
converges, that is sufficient for existence of equilibrium for a specific set of parameters ${ }^{18}$

A much greater problem of this kind of models is the potential multiplicity in the number of equilibria. This is the reason for choosing to focus on a symmetric equilibrium. That is, two firms that are at identical states are restricted to follow the same strategies. In our setup, this amounts to say that if firm $f$ is in state $(i, j, f)$, he expects his competitor $f_{-}$to behave in the same way as firm $f$ would behave being in state $\left(j, i, f_{-}\right)$. This assumption is standard in the literature of Markov perfect games and serves also to simplify greatly the computational burden of the model. We also check the multiplicity of equilibria by allowing the numerical algorithm to start from different initial conditions. No case was identified where there was more than one equilibrium 19

\subsection{Computation}

To compute the symmetric MPE, we use a variant of the algorithm described in Pakes and McGuire (1994). The algorithm works iteratively. It takes a value function $\widetilde{V}(i, j, f)$ and a policy function $\widetilde{x}(i, j, f)$ as its input and generates updated value and policy functions as its output. Each iteration proceeds as follows: First, we use equation (4) to compute a firm $f$ 's investment strategy $x(i, j, f)$ taking the other firm's investment strategy to be given by $\widetilde{x}\left(j, i, f_{-}\right)$. In doing so, we use $\widetilde{V}(i, j, f)$ and $\widetilde{x}\left(j, i, f_{-}\right)$to compute $W_{f^{\prime}}\left(i^{\prime}\right)$. Second, we compute the payoff $V(i, j, f)$ associated with firm $f$ using $x(i, j, f)$ and $W_{f^{\prime}}\left(i^{\prime}\right)$. The iteration is completed by assigning $V(i, j, f)$ to $\widetilde{V}(i, j, f)$ and $x(i, j, f)$ to $\widetilde{x}(i, j, f)$. The algorithm terminates once the relative change in the value and the policy functions from one iteration to the next are below a prespecified level of tolerance. All programs are written in Matlab 6.5 and are available upon request.

\subsection{Parametrization}

We consider a time period as a year and calculate the discount factor, $\beta$, from an interest rate of approximately $8 \%$. This implies a discount factor of $\beta=0.925$. Even though the parameter of the marginal cost of investment, $c$, affects in an important way the long-run behavior of the industry, the qualitative results tend to be maintained. For simplicity, we

\footnotetext{
${ }^{18}$ Convergence of the numerical algorithm is a sufficient condition for the existence of a $\varepsilon$-equilibrium. See Benkard (2004).

${ }^{19}$ Similar approaches to analyze industry evolution are presented in Besanko and Doraszelski (2004), Benkard (2004), Doraszelski and Markovich (2006) and Besanko et.al. (2006).
} 
assume initially $c=0.5$.

The parameter that measures the level of competition is perhaps the most influential and relevant parameter in our results. Given that no empirical estimation of this parameter is available for the case of a network industry, the results presented in this paper consider different specifications. We believe that, as has been widely highlighted, network goods are based on very fast-paced innovations, that very low values of $\delta$ are not very realistic.

We assume that the (numerical) values of the qualities are given by $q=0,1, \ldots, M-1$ for each state $i=1,2, \ldots, M$, respectively. That is, to quality state 1 corresponds a numerical value of 0 , to quality state 2 corresponds a numerical value of 1 , and so on. We use $M=15$ as a benchmark. Given the role of the outside option, it is natural to normalize to 0 the lower possible relative quality. It is assumed that $0<\omega<1$. This assumption is important to maintain the consistency of the expectations rules explained above.

We recognize that the potential relevance of the conclusions provided in this paper are still to be corroborated by empirical analysis of network industries.

\section{Results}

In this section we present the results from our model of dynamic duopoly competition with network externalities and endogenous and stochastic R\&D processes. We start by reporting the analysis of the level and determinants of $\mathrm{R} \& \mathrm{D}$ incentives, their implications for industry evolution and the social efficiency of the market outcome. We relate our results to the existing literature on competition in network industries taking into account a dynamic perspective. Subsequently, we compare our results with the literature on innovation and competition and examine the role of network externalities in this relationship. Finally, we derive some policy recommendations and some empirical implications as a motivation for further research.

\subsection{R\&D Incentives, Industry Evolution and Social Efficiency}

We report the findings of this section in three steps. First, we describe the equilibrium incentives to invest in R\&D (i.e. equilibrium policy functions), the impact of network externalities and the influence of relevant parameters (i.e. cost of innovation, level of 
competition) on those incentives. Second, we exploit the markov process that characterizes the equilibrium of the industry and investigate whether the impact of network externalities on the equilibrium R\&D levels influences the dynamic evolution of the industry. In particular, we discuss the short-run (transitory) dynamics, as well as the long-run (steadystate) dynamics of the underlying markov process. And third, we briefly discuss the social efficiency of the market outcome.

R\&D Incentives. The equilibrium R\&D investments (i.e. equilibrium policy functions) constitute the core of the model as they represent the main strategic variable that drives industry dynamics. For a firm, higher investments in R\&D increase the probability of observing a better quality in the next period, and hence, improve the conditions under which product market competition takes place. However, investment are costly to perform, so firms must consider the gains of additional investments in terms of expected cash flows (i.e. higher qualities allow for higher prices) and strategic considerations (i.e. higher qualities reduce the threat from a competitor) in comparison with the associated cost.

In our model, this $\mathrm{R} \& \mathrm{D}$ competition takes the form of a preemption race. This is a direct consequence of our dynamic modeling strategy of homogeneous consumers under Bertrand quality competition. Specifically, the model shows that the two firms invest heavily in $\mathrm{R} \& \mathrm{D}$ as long as their quality levels are equal or very close to each other. In these situations (i.e. neck-and-neck configurations) the potential gains of developing a slightly better quality may have profound and favorable economic consequences for the innovative firm. Therefore, $R \& D$ incentives are very high, as they can decide the outcome of the preemption race. In addition, and consistent with preemption race models, we show that once asymmetric quality levels are realized, $R \& D$ investment decrease at a fast pace. That is, the preemption race is practically decided in favor of the more innovative firm, and therefore, the incentives to invest for the two firms are reduced after technological leadership is decided. R\&D investments are reduced because for the innovative (leading) firm there is no imminent threat and for the competitor (follower) the potential gains from innovating are drastically reduced.

To illustrate this situation, Figure 1 presents the equilibrium behavior of the main components of the model (i.e. R\&D investments (equilibrium policy functions), per period profits (product market competition) and discounted future cash-flows (equilibrium value functions)). The top panel shows the equilibrium values for the incumbent firm, while 
the lower panel shows the equilibrium values for the entrant firm. Variables are plotted for a given firm as a function of the state space (i.e. qualities) of the industry. As can be seen from the first column, R\&D investment shows the preemption race behavior just described: Fierce competition under neck-and-neck quality configurations. The next two columns show the payoffs of the game (i.e. profits and equilibrium value functions) and highlight the benefits of winning the preemption race. That is, payoffs are greater, the higher the technological advantage that a firm can achieve.

Impact of network externalities. How does the presence of network externalities affect the nature of competition just described for this industry?. The model shows that the preemption race behavior of the industry is maintained. However, network externalities unambiguously increase the incentives to invest in $R \& D$, increasing the toughness of the technological race. That is, the existence of an installed base increases the benefits from innovating, as well as the cost from not innovating. Figure 2 shows the difference in $R \& D$ investments levels from having different values of the parameter that measures the extent of the network benefits (i.e. $\omega=0.4, \omega=0.6$ and $\omega=0.8$ ). In this Figure, we consider the level of competition as $\delta=0.6$, but the results are robust to different parameters' configurations. Not surprisingly, given the preemption race behavior, the impact of network externalities on the $R \& D$ incentives is stronger for the case when the quality levels are very similar between competitors. That is, in the presence of network externalities, the achievement of a higher quality level (relative to that of the competitor) not only permits to capture the market, but implies an "installed base" advantage that protects the incumbent firm in the case of quality ties. Therefore, network externalities provide a strong incentive to achieve a quality innovation in order to enjoy the benefits of the installed base of consumers. At the same time, when network benefits are important, losing a quality advantage makes more difficult to compete in the market.

These results are consistent with the literature on competition in network industries. For instance, as stated by Evans and Schmalensee (2001), network industries " compete for the market" and, in consequence, investments in R\&D represent the main strategic tool for competition. Hence, network externalities promote R\&D efforts because they provide the (only) mean to secure market survival. In addition, Katz and Shapiro (1994) state that the frequent introduction of new technologies is a common pattern in network industries. Moreover, they argue that this frequent innovation process goes actually beyond the level of innovation that is socially optimal. They term this situation as "insufficient 
friction", as the introduction of innovations is smoother than the level that would be socially optimal. In a different strand of literature, Aghion et. al. (2005) show that in innovative industries, $R \& D$ investments allow firms to escape from competition. That is, even though the benefits of innovation might be reduced by a strong market competition (i.e. rent dissipation), these benefits more than compensate the losses from not innovating. They termed this phenomenon as the "escape effect" and we can interpret the role of network externalities as enhancing the divergence between the benefits of innovating and the potential loses of not doing so.

In addition, the incentives to invest in $\mathrm{R} \& \mathrm{D}$ are also related to some relevant parameters. Figure 3 presents the equilibrium investment levels exhibited by firm $f$ as a function of its own quality level, the quality of its competitor, the level of competition (i.e. $\delta$ ) and the marginal cost of investment (i.e. c).20. This figure highlights two main features of the model that will be important, in particular the second, in understanding the impact of network externalities. First, the investment levels are, for any parameter values, decreasing in their marginal costs. The intuition is straightforward.

Second, the investment levels behave non-monotonically to variations in the level of competition $\delta$. In particular, the investment levels tend to follow an inverted U-shaped trajectory. Recall that $\delta$ represents the potential exogenous probability of a decrease in the firm's own relative quality level. A consequence of the competitive environment. This implies that the level of investments inside an industry are related, non-monotonically, to the level of competition ${ }^{21}$ We present the implications of this observation in the next subsection.

Industry Evolution. Given that the investment levels determine the probability of reaching a higher quality level, they impact decisively the long-run performance of the industry. Moreover, given the equilibrium concept adopted, the industry evolves in a markov fashion. In order to exploit this feature of the model, and to relay less on simulations, we construct the distribution over future quality states (i.e. transition matrix) and analyze the impact of network externalities on this distribution. In particular, we compute the transient (short-run) distribution of the stochastic process associated with the evolution of the industry.22 In addition, we compute the limiting (long-run)

\footnotetext{
${ }^{20}$ For simplicity, Figure 3 presents the results for the case of only 3 quality levels but the result extends to a state space of higher dimension

${ }^{21}$ This result is reminiscent of the inverted U-shape relation between the level of competition in an industry and the incentives to innovate found in Aghion et. al (2005) and Aghion and Griffith (2005).

${ }^{22}$ Given an initial state, the transient distribution determines the probability of being in any other state
} 
distribution that describes the steady state behavior of the industry. It shows the invariant probability that, for any initial state, in the long run a firm will find itself in any particular state ${ }^{23}$ With these tools, we are able to analyze the evolution of the industry over different time horizons and to evaluate the impact on profits, investments and welfare of different parameter configurations from a time perspective.

In our model, the transition to the steady-state is relatively slow. On average, this transition (the number of periods after which the transient distribution is equal to the limiting distribution) occurs in approximately 25-30 periods. Moreover, the model shows, as expected, that in the short-run industry exhibits a neck-and-neck structure. That is, before the steady-state is reached, firms compete fiercely for dominance if their quality difference is not too big. This result can be seen from Figures 4, 5, and 6 . These Figures plot the transient distribution over different time horizons taking as initial condition a duopoly with equal quality levels. In particular, Figure 4 shows the transient distribution, in the left panel, after 5 periods. For this Figure, the initial configuration of the industry is a duopoly with equal quality levels $\left(a_{i}=4\right)$, in which one of the firms exhibits an installed base of consumer.

The middle panel shows the change in the transient distribution for increasing the parameter that measures the extent of network externalities from $\omega=0.4$ to $\omega=0.8$. This allows us to see the impact of network externalities. As can be seen, the probability of observing neck-and-neck situations after 5 periods is increased as a consequence of the presence of network externalities. This results holds for every parameter configurations. In particular, Figures 5 and 6 show the same result but considering the case of a longer horizon, that is, they present the transient distribution after 15 and 25 periods.

It can also be shown, that in this transition process, R\&D incentives are higher that the level reached in the long-run. As Figure 6 suggests, in the long-run the industry is highly concentrated. This is an outcome of the preemption race. This result is robust to any parametrization and it follows from the nature of competition.

Social efficiency. One of the main objectives of this paper is to analyze the social efficiency of the private incentives to innovate. In order to do this, we solve the social

after a prespecified number of periods. This distribution is defined as follows. For $M$ possible states, let $P$ be the $M^{2} \times M^{2}$ transition matrix of the markov process of industry evolution that can be computed using the equilibrium investment levels. Then, the marginal (transient) distribution after $T$ periods is given by $a^{(T)}=a^{(0)} P^{T}$, where $a^{(0)}$ is the $1 \times M^{2}$ initial distribution.

${ }^{23}$ The $1 \times M^{2}$ limiting distribution $\pi$, is the distribution that solves the system of linear equations $\pi=P \pi$, where $P$ is the $M^{2} \times M^{2}$ equilibrium transition matrix. 
planner problem. This is done by considering the case of a monopolist in charge of the two technologies (i.e. network goods) and that prices equal marginal cost (i.e. zero and therefore maximizing consumer surplus which is equal to social surplus in our homogeneous consumer framework presented in equations (1) and (2)).

The main result obtained by analyzing the problem of the social planner is that there is too much $R \& D$ in the industry. The main implication of this result is that there is too much introduction of improved goods in the market. Given that the social planner internalizes the costs associated with the quality improvements, it tends to concentrate investment in the firm that exhibits a quality advantage. This result implies that a technology that exhibits a better quality tend to stay as the preferred technology because it maximizes the network benefits enjoyed by the population. As a consequence, this result also shows that the market outcome induces too much introduction of new incompatible technologies.

Table1 1 presents some results for the social planner's problem. In particular, it presents two important results. First, a high level of competition (ie. a high $\delta$ ) reduces the expected social surplus and also reduce the expected investment levels. And second, it states that with a high level of competition, the extent of network externalities is critical in determining the size of the inefficiency associated with the investment levels.

\subsection{Competition, Innovation and Policy Implications}

One advantage of the model presented in this paper, is that it allows us to analyze the relationship between the outcome of the product market and the level of competition. In particular, we try to evaluate some assertions present in the literature about innovative industries.

We perform this analysis in three steps. First, we discuss the impact on competition on per period profits and on the equilibrium level of $R \& D$ investments. This allows us to compare our results with novel results on the literature on innovation and competition. In particular, we related our findings to those of Aghion et. al. (2005) and Aghion and Griffith (2005). Second, we investigate how the presence of network externalities affects this relationship between innovation and competition. We provide an intuition for the results. And third, we perform numerical simulations to evaluate the interaction between variables that can be affected by public policy (i.e. cost of R\&D, level of competition) and the extent of network externalities. We provide some results concerning the ability 
of public policy to increase consumers' welfare in network industries.

Competition and innovation. In order to evaluate the impact of the level of competition on the level (or pace) of innovation observed in a network industry, we need a (theoretical) variable that mirrors the level of competition and a (theoretical) variable related with the amount of innovation exhibited by the industry. We use the level of competition (i.e $\delta$ ) as a measure of the level of competition faced by the industry. According to Boone $(2000,2001)$, if a parameter increase in the chosen variable (i.e $\delta$ ) increases the relative profits of more advanced firms (i.e the profitability of firms with a higher quality level) such variable represents a suitable measure of the level of competition. This condition is corroborated by the model.

We approximate the level of innovation by calculating the conditional expected value of the R\&D investments observed in equilibrium. Due to our modeling strategy, the probability of innovation is stochastically increasing (in the first-order stochastic dominance sense) in the level of R\&D investments. As an alternative measure, we also use the intensity of R\&D (i.e. R\&D investments divided by sales).

The main result we obtain states that the impact of the level on competition on the R\&D equilibrium levels depends on the time horizon considered. In particular, by using the tools from the stochastic process literature employed in the previous subsection, we show that in the short-run, the level of innovation and the level of competition exhibit and inverted-U relationship. In contrast, the model shows that in the long-run, a higher level of competition is always associated with higher levels of innovation. These results are presented in Table 2 .

In order to understand the implications of these findings, we briefly review the existing literature on the topic. Specifically, the Schumpeterian approach to market innovation states that in the event of an increase in competition, firms tend to reduce their innovation levels because higher competition dissipates some of the rents associated with higher market power. This has been termed the "Schumpeterian effect". However, it has been empirically shown that in some cases this relation is positive. ${ }^{24}$

This case of direct relation between the level of competition and the incentives to innovate can be explained as follows. Although it could be the case that the expected rents from innovating are reduced by the presence of higher competition (i.e. as the Schumpeterian view sustain), a higher level of competition may imply higher innovation

\footnotetext{
${ }^{24}$ See Geroski (1995), Nickell (1996) and Blundell, Griffith and Van Reenen (1999).
} 
if the rents from not innovating are much lower (i.e. even though under higher competition innovation is less profitable, it is better than not innovating). This has been termed the "escape effect". This distinction between post-innovation and pre-innovation rents has been explained in the literature by the preemption race literature 25 . However, this latter literature does not consider the impact of the level of competition on this interaction between post-innovation and pre-innovation rents (i.e. the determinants of the "escape effect"). This paper allows us to analyze this impact.

In general terms, the two effects (i.e. the Schumpeterian and escape effects) have been made compatible by Aghion et al. (1997), Aghion et al. (2005) and Aghion and Griffith (2005). In particular, the level of innovation behaves as an inverted U-shape function in relation to the level of competition. ${ }^{26}$ That is, for low levels of competition, the investment level tends to increase as competition become fiercer (i.e. escape effect) and, eventually, starts declining in the presence of high competition (i.e. Schumpeterian effect). This is the result we obtain in the short-run.

However, we show that in the long-run, the escape effect dominates the Schumpeterian effect. The main implication of this result is that in order to foster innovation in the longrun, competition should be promoted instead of limited. Below, we show some simulations that present some specific results related to this implication.

Policy implications. We performed a number of simulations in order to track the evolution of the industry and to evaluate the impact of changes in policy relevant parameters. In particular, we consider the level of competition (i.e. $\delta$ ) and the role of the cost of R\&D (i.e. c) and derive some results in terms of consumer welfare. These results are summarized in Figures 7 and 8 where we plot the evolution of the qualities of the two firms, the associated R\&D incentives and per-period profits. Tables 3, 4 and 5 present more detailed results. In Figure 7, we consider the case of low level of competition and a high cost of R\&D. In Figure 8, we increase the level of competition, while reducing the cost of performing $R \& D$ investments. An increase in the level of competition can be associated with any action or measure that improves the strategic position of a firm's competitors. For example, policy measures as mandatory licensing or diffusion of information on the operability of new technologies could be interpreted as an increase in parameter $\delta 27$

\footnotetext{
${ }^{25}$ See Reinganum (1989)

${ }^{26}$ This theoretical finding is in line with the empirical results of Scherer (1967), Levin et al. (1985) and is specifically tested in Aghion et al. (2005).

${ }^{27}$ Evans and Schmalensee (2005) discuss the measures taken after the conclusion of the Microsoft trial.
} 
We summarize three main findings. First, by reducing the cost of performing R\&D (i.e. parameter $c$ ), short-run competition is intensified, reducing the probability of observing a single forever-dominant incumbent firm. Second, an increase in the level of competition without a reduction in the cost of R\&D may actually increase the probability of observing an early industry leader. Therefore, in an innovative industry, policies that increase the level of competition are beneficial for innovation, but should be implemented with measures that increase the incentives to innovate in order to provide a higher surplus to consumers. And third, an increase in the level of competition and a reduction in the costs of $R \& D$ might reduce the temporary dominance of leading firms, increase competition and increase consumers' surplus. That is, the preemption race lasts, on average, a longer period of time. As can be seen in the first panel of Figure 7, the state (quality) space shows that the race lasts around 65 periods, after which a clear winner is observed. In contrast, Figure 8 shows (first panel) how an increase in the level of competition and a reduction in the costs associated to $R \& D$ activities are translated into a longer race (i.e. to 95 periods).

The main implication of these results is that the larger the time length of the race, the higher the surplus enjoyed by consumers. As can be seen from Figure 8 (second panel), the two firms invest more in $R \& D$ as a result of an increase in the level of competition. This is consistent with the "escape effect" emphasized by Aghion et. al (2005), That is, as competition becomes stronger, the strategic value of $R \& D$ is increased, and therefore firms invest more aggressively to develop a new innovation. As a consequence, a higher technological advance is observed (higher qualities of the network goods). At the same time, a longer race implies that the profits earned by the firms are reduced as shown also in Figure 8 (third panel). Therefore, a greater part of the surplus generated in this industry is transferred to consumers, by means of lower prices and better available technologies.

\section{Conclusions}

In this paper, we proposed a dynamic model of quality competition in the presence of network externalities that adapts the Markov-perfect equilibrium framework presented in Ericson and Pakes (1995). We solved the model numerically using a variant of the

Among the measures adopted, they report that for example "Microsoft must license to third parties under reasonable and non-discriminatory terms any intellectual property rights needed to exercise any of the options or alternatives provided to them under [the remedy provisions]". 
algorithm presented in Pakes and McGuire (1994). Incentives to invest in R\&D are derived endogenously. The focus of this paper was twofold. First, to develop a model flexible enough to analyze the impact of network externalities on R\&D incentives along several dimensions. For example, to make the distinction between short and long-run, to be able to compare the results with novel results from the innovation literature and to explicitly account for the role of the level of market competition on market outcomes. Second, by being able to relate the results to a wide range of literature, the model attempts to provide policy recommendations for network industries where innovations are the main driver of dynamic performance.

We departed from the current literature on network industries by focusing our analysis on four main areas. First, we considered endogenous and uncertain R\&D efforts taking into account the way consumers form expectations. Second, we embedded our analysis in a fully dynamic framework. Third, we explicitly considered the impact on the short and long-run social efficiency of the R\&D incentives that drives the evolution of the network industry and the role of competition policy in this evolution. And fourth, we provided an assessment of the question whether competition policy should be cautious in dynamically competing industries.

We showed three main results. First, network externalities affect positively the incentives to invest in $\mathrm{R} \& \mathrm{D}$. Competition resembles a preemption race and installed bases increase the prize that can be won by a successful competitor. As a consequence, it is not surprising that market performance tends to over-invest in R\&D. Second, network externalities have an important impact on the dynamic evolution of the industry. Although in the long-run a single firm dominates the market (i.e. wins the race), in the short-run competition is stronger and concentrated on neck-and-neck technological configurations. And third, policy measures that increase the level of competition and extend the shortrun behavior of the industry have an important impact on consumer welfare and $R \& D$ incentives.

We recognize several areas of further research on $R \& D$ incentives in the presence of network externalities. A deeper analysis of the different ways about how consumers form expectations (or coordinate) may provide new insights on the interplay between $R \& D$ incentives in network industries. In addition, the analysis of compatibility decisions must also be considered given its obvious relevance in these industries but for the time being beyond the scope of the present paper. 


\section{References}

Aghion, P., C. Harris, and J. Vickers, (1997), "Competition and Growth with Step-byStep Innovation: An Example", European Economic Review, Papers and Proceedings, 771-782.

Aghion, P., C. Harris, P. Howitt, and J. Vickers, (2001), "Competition, Imitation and Growth with Step-by-Step Innovation", Review of Economic Studies, 68, 467-492.

Aghion, P., N. Bloom, R. Blundell, R. Griffith and P. Howitt, (2005), "Competition and Innovation: An Inverted-U Relationship", Quarterly Journal of Economics, 120, 701-728.

Aghion, P. and R. Griffith, (2005), "Competition and Growth. Reconciling Theory and Evidence". Zeuthen Lectures. MIT Press.

Aghion, P., and P. Howitt, (1992), "A Model of Growth through Creative Destruction", Econometrica, 60, 323-51.

Arthur, W.B., (2000), "Myths and Realities of the High-Tech Economy", Talk given at Credit Suisse First Boston Though Leader Forum,Santa Fe Institute.

Bagnoli, M., S. Salant, and J., Swierzbinski (1989), "Durable-goods Monopoly with Discrete Demand", Journal of Political Economy, 97, 1459-1478.

Benkard, C. L., (2004), " A Dynamic Analysis of the Market for Wide-Bodied Commercial Aircraft", Review of Economic Studies, 71, 581-611.

Bensaid, B. and Lesne, J.P., (1996), "Dynamic Monopoly Pricing with Network Externalities", International Journal of Industrial Organization, 14, 837-855.

Besanko, D. and U. Doraszelski, (2004), "Capacity Dynamics and Endogenous Asymmetries in Firm Size", RAND Journal of Economics, 35, 23-49.

Besanko, D., U. Doraszelski, Y. Kryukov, and M. Satterthwaite, (2006), "Learning-byDoing, Organizational Forgetting, and Industry Dynamics", Working Paper, Harvard University. 
Besen, S. and J. Farrell, (1994), "Choosing How to Compete: Strategies and Tactics in Standardization", Journal of Economic Perspectives, vol. 8, pp. 117-131.

Boone, J., (2000), "Competitive Pressure: The Effects on Investments in Product and Process Innovation", RAND Journal of Economics, 31, 549-69.

Boone, J., (2001), "Intensity of Competition and the Incentive to Innovate", International Journal of Industrial Organization, 19, 705-26.

De Bijil, P.W.J. and S. Goyal, (1995), "Technological Change in Markets with Network Externalities", International of Industrial Organization, 13, 307-325.

Blundell, R., R. Griffith, and J. Van Reenen, (1999), "Market Share, Market Value and Innovation in a Panel of British Manufacturing Firms", Review of Economic Studies, $66,529-554$.

Caballero, R. and A. Jaffe (1993), "How High are the Giants Shoulders? An Empirical Assessment of Knowledge Spillovers and Creative Destruction in a Model of Economic Growth", NBER Macroeconomic Annual, 15-74.

Choi, J.P., (1994), "Irreversible Choice of Uncertain Technologies with Network Externalities", RAND Journal of Economics, 25, 382-401.

Dasgupta, P. and J. Stiglitz, (1980), "Industrial Structure and the Nature of Innovative Activity", Economic Journal, 90, 266-293.

Doraszelski, U. and S. Markovich, (2006), "Advertising Dynamics and Competitive Advantage", RAND Journal of Economics, forthcoming.

Doraszelski, U. and A. Pakes, (2006), "A Framework for Applied Dynamic Analysis in I.O.", forthcoming in Mark Armstrong and Robert Porter (eds.) Handbook of Industrial Organization, Volume 3, North-Holland, Amsterdam.

Doraszelski, U. and M. Satterthwaite, (2005), "Foundations of Markov-Perfect Industry Dynamics: Existence, Purification and Multiplicity", Working Paper, Harvard University.

Ericson R. and A. Pakes, (1995), "Markov-Perfect Industry Dynamics: A Framework for Empirical Work", Review of Economic Studies, 62, 53-82. 
Evans, D. E. and R. Schmalensee, (2001), "Some Economic Aspects of Antitrust Analysis in Dynamically Competitive Industries", NBER Working Paper No. 8268.

Evans, D. E., Nichols, A. L. and R. Schmalensee, (2005), "U.S. v. Microsoft: Did Consumers Win?", NBER Working Paper No. 11727.

Farrell, J. and M. Katz, (2005), "Competition or Predation? Consumer Coordination, Strategic Pricing and Price Floors in Network Markets", Journal of Industrial Economics, LIII, 203-231.

Farrell, J. and G. Saloner, (1985), "Standardization, Compatibility and Innovation", RAND Journal of Economics, vol. 16, 70-83.

Farrell, J. and G. Saloner, (1986), "Installed Base and Compatibility: Innovation, Product Preannouncement, and Predation", American Economic Review, 76, 940-955.

Fudenberg, D. and J. Tirole, (2000), "Pricing a Network Good to Deter Entry", Journal of Industrial Economics, XLVIII, 373-390.

Gabel, L., (1991), "Competitive Strategies for Product Standards", London: McGraw Hill.

Geroski, P., (1995), "Market Structure, Corporate Performance and Innovative Activity", Oxford University Press.

Grindley, P., (1995), "Standards Strategy and Policy. Cases and Stories", Oxford University Press.

Katz, M. and C. Shapiro, (1985), "Network Externalities, Competition and Compatibility", American Economic Review, vol. 75, 424-440.

Katz, M. and C. Shapiro, (1986), "Technology Adoption in the Presence of Network Externalities", Journal of Political Economy, 94, 822-84.

Katz, M. and C. Shapiro, (1992), "Product Introduction with Network Externalities", Journal of Industrial Economics, 40, 55-84.

Katz, M. and C. Shapiro, (1994), "Systems Competition and Network Effects", Journal of Economic Perspectives, vol. 8, pp. 93-115. 
Kristiansen, E.G., (1996), "R\&D in Markets with Network Externalities, International Journal of Industrial Organization, Vol. 14, pp. 769-784.

Levin, R., W. Cohen, and D. Mowery, (1985), "R\&D Appropriability, Opportunity, and Market Structure: New Evidence on some Schumpeterian Hypotheses", American Economic Review, Papers and Proceedings, 75, 20-24.

Maskin, E. and J. Tirole, (1988), "A Theory of Dynamic Oligopoly: I \& II", Econometrica, 56, 549-600.

Nickell, S., (1996), "Competition and Corporate Performance", Journal of Political Economy, 104, 724-746.

Pakes, A. and P. McGuire, (1994), "Computing Markov-Perfect Nash Equilibria: Numerical Implications of a Dynamic Differentiated-Product Model", RAND Journal of Economics, 25, 555-589.

Reinganum, J., (1989), "The Timing of Innovation: Research, Development and Diffusion". In R. Schmalensee and R. Willig, (eds.) (1989). Handbook of Industrial Organization, North-Holland. 849-908.

Shapiro, C. and H. Varian, (1999). Information Rules: A strategic guide to the network economy. Harvard Business School Press. 

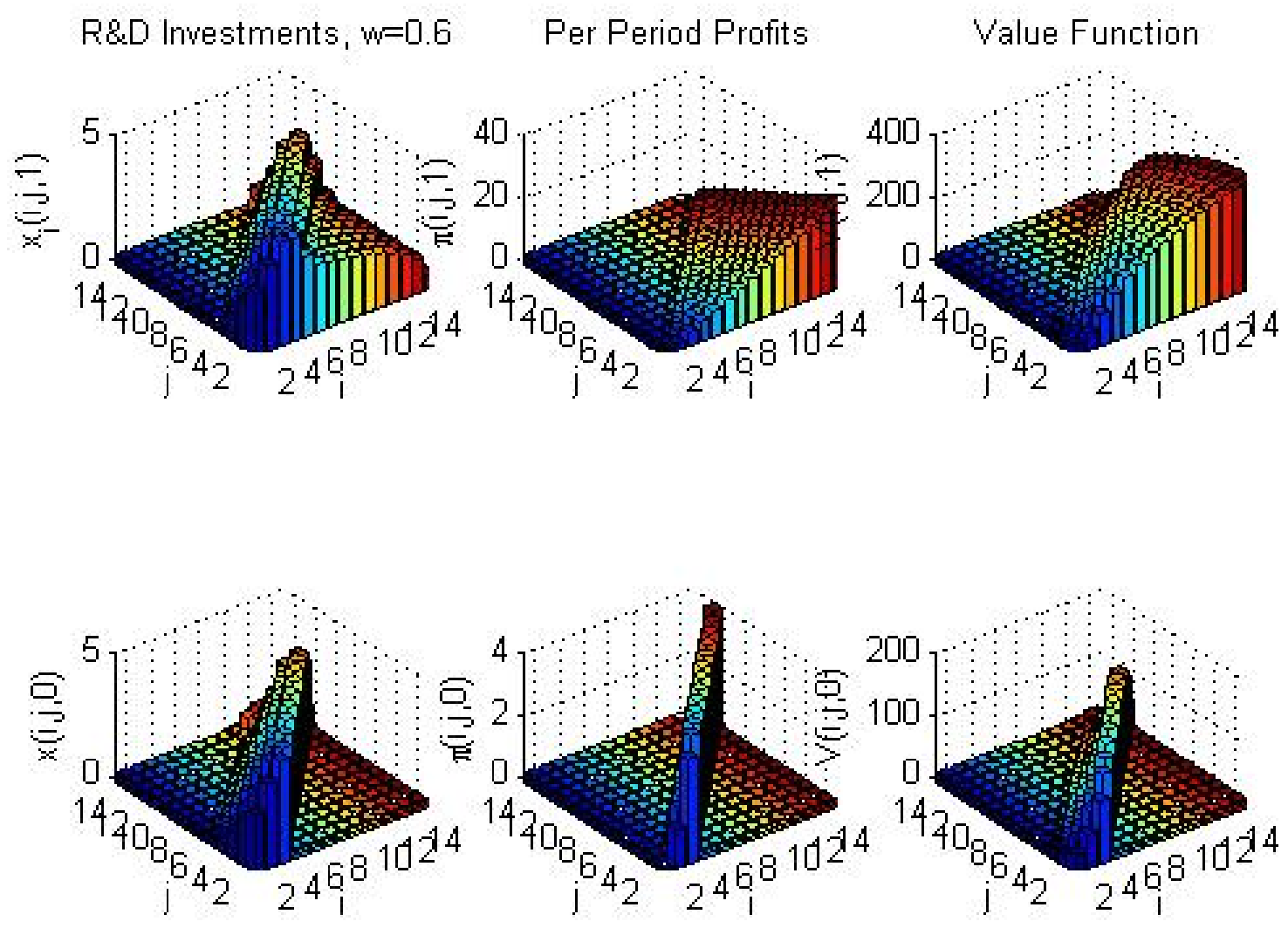

Figure 1: Main Variables. Incumbent firm (top panel). Entrant firm (bottom panel). 

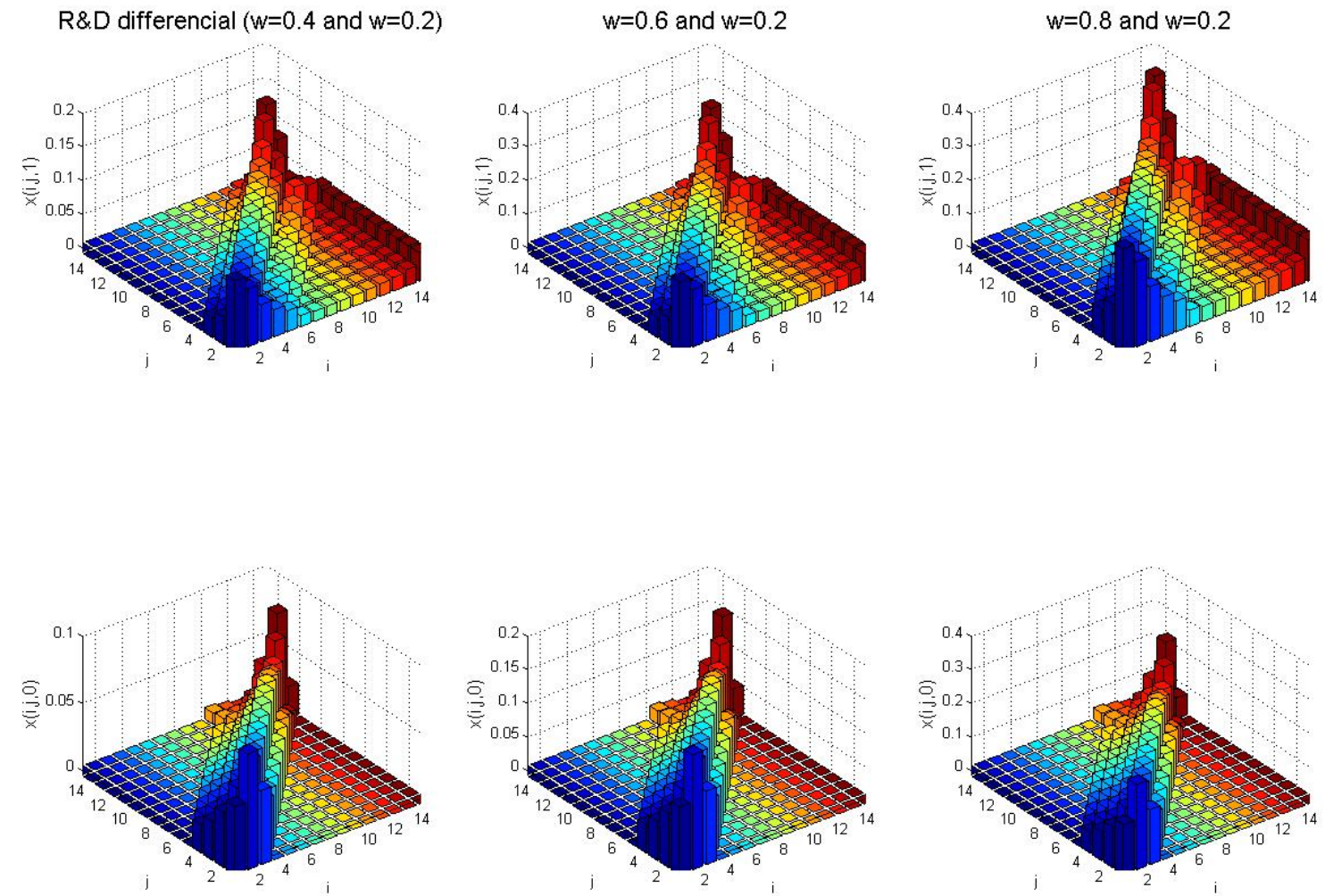

Figure 2: Impact of Network Externalities on R\&D levels. Incumbent firm (top panel). Entrant firm (bottom panel). 

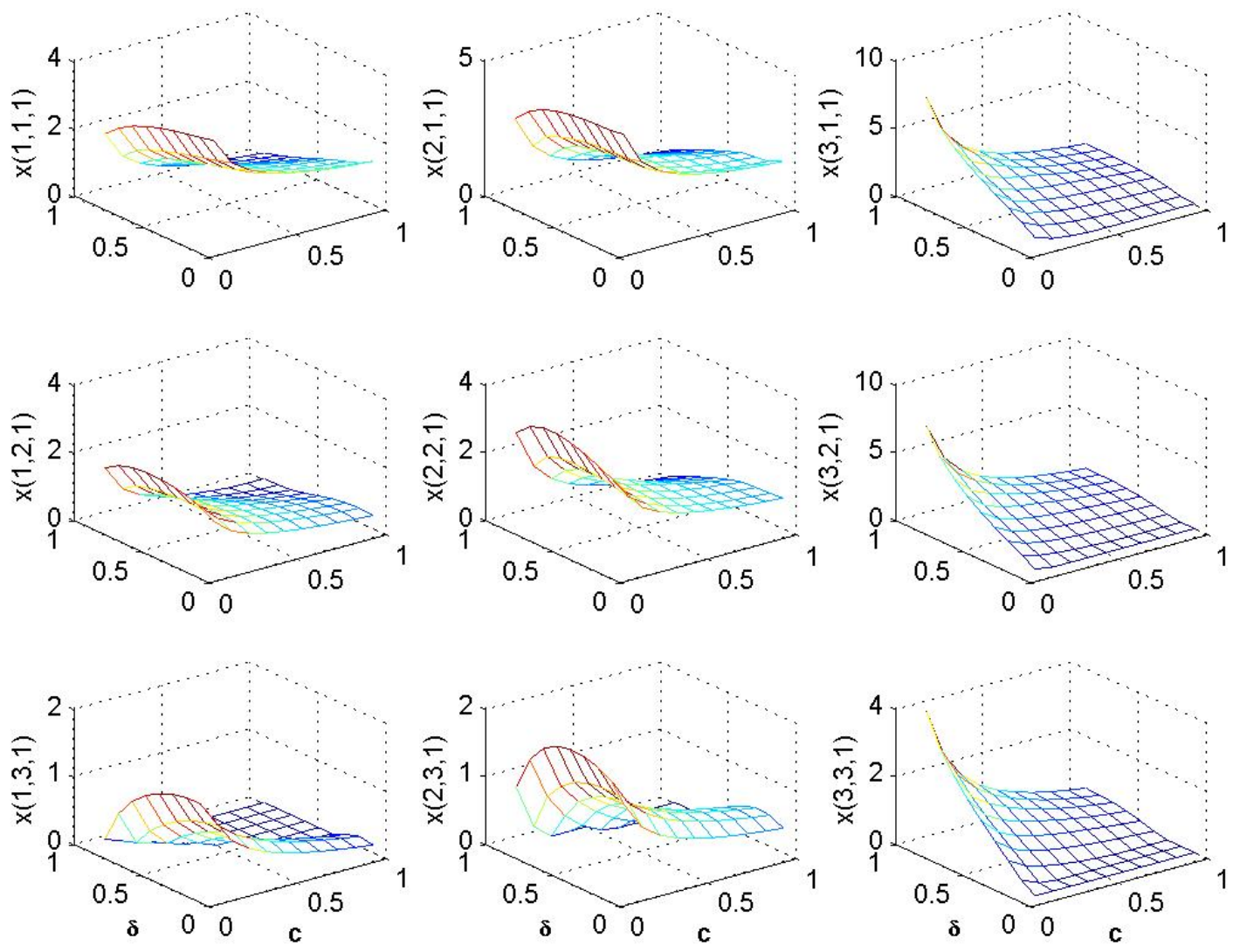

Figure 3: R\&D Levels (as a function of the investments' costs $c$ and the level of competition $\delta)$. This graph is calculated for the case of 3 quality levels $\left(a_{i}=0,1,2\right)$ 

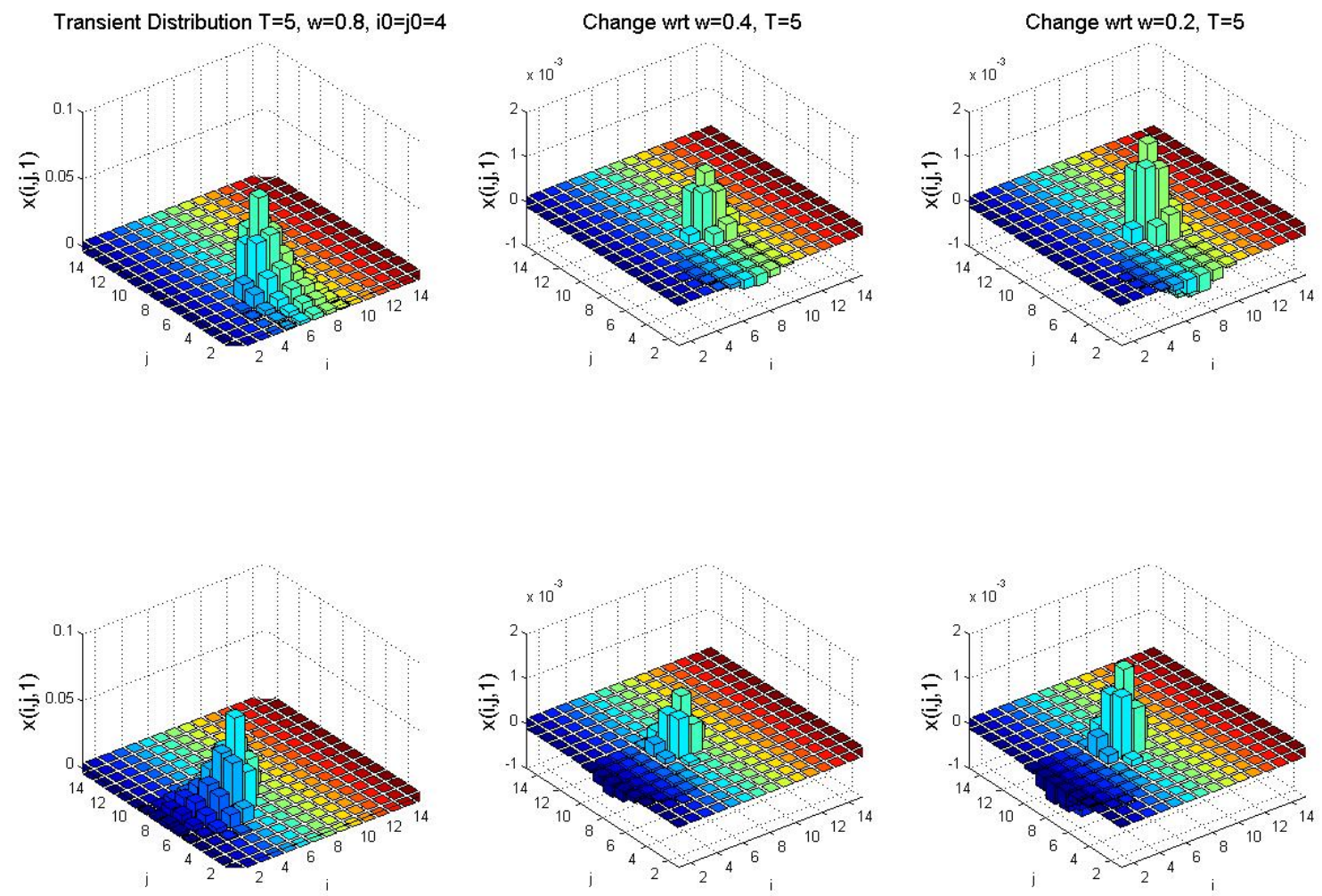

Figure 4: Transient Distribution (short-run) for $T=5$. Incumbent firm (top panel). Entrant firm (bottom panel). 

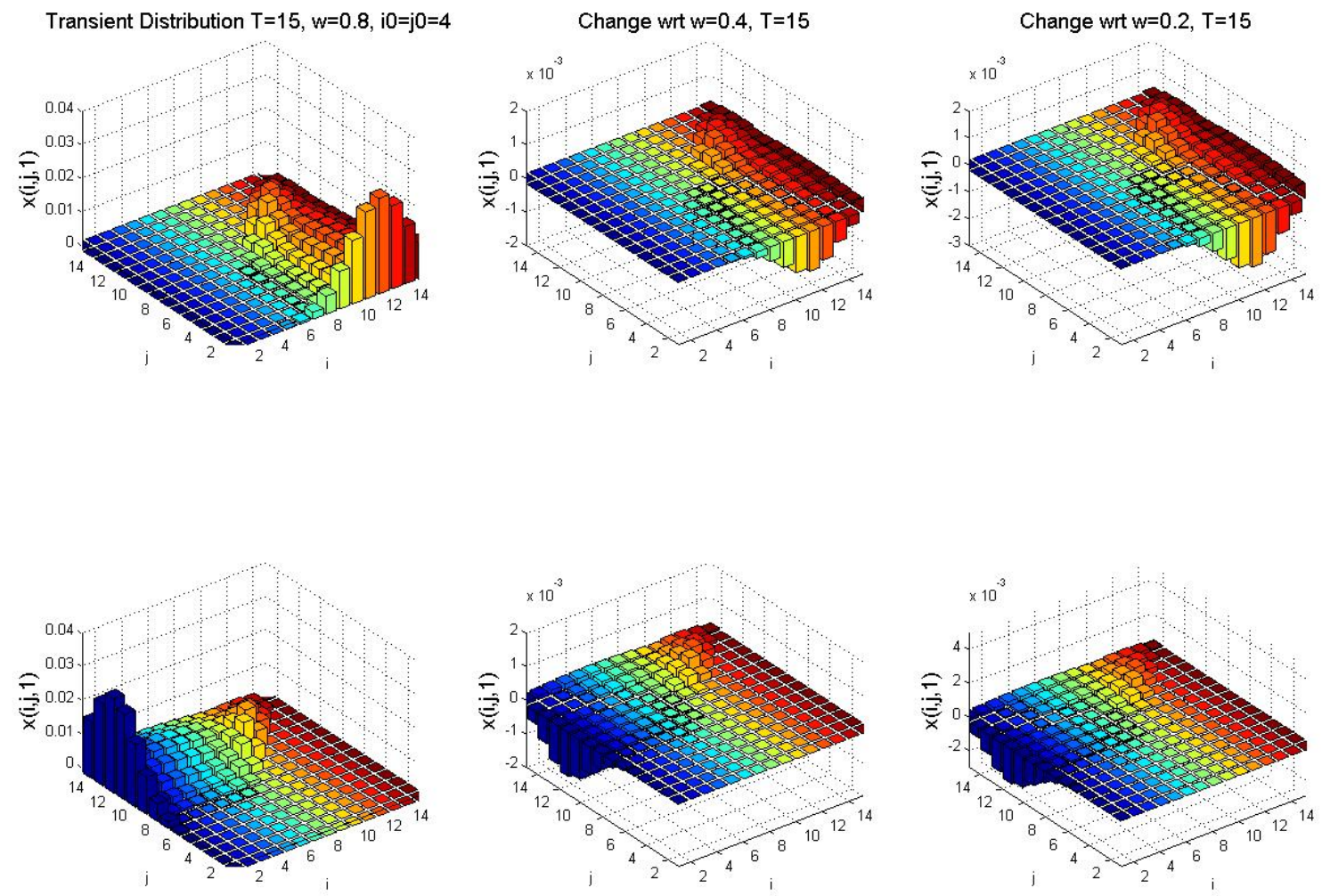

Figure 5: Transient Distribution (short-run) for $T=15$. Incumbent firm (top panel). Entrant firm (bottom panel). 

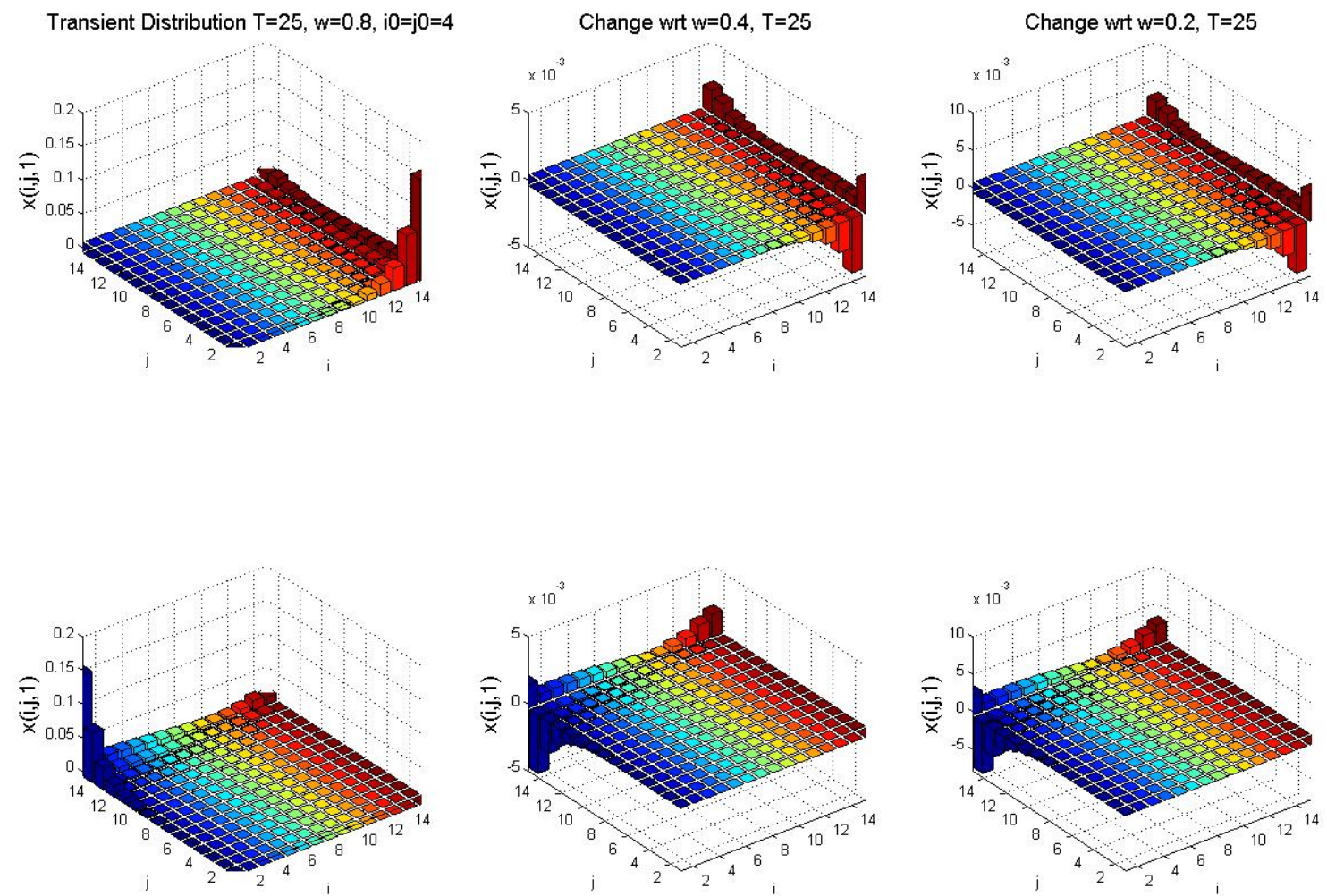

Figure 6: Transient Distribution (medium-run) for $T=25$. Incumbent firm (top panel). Entrant firm (bottom panel). 

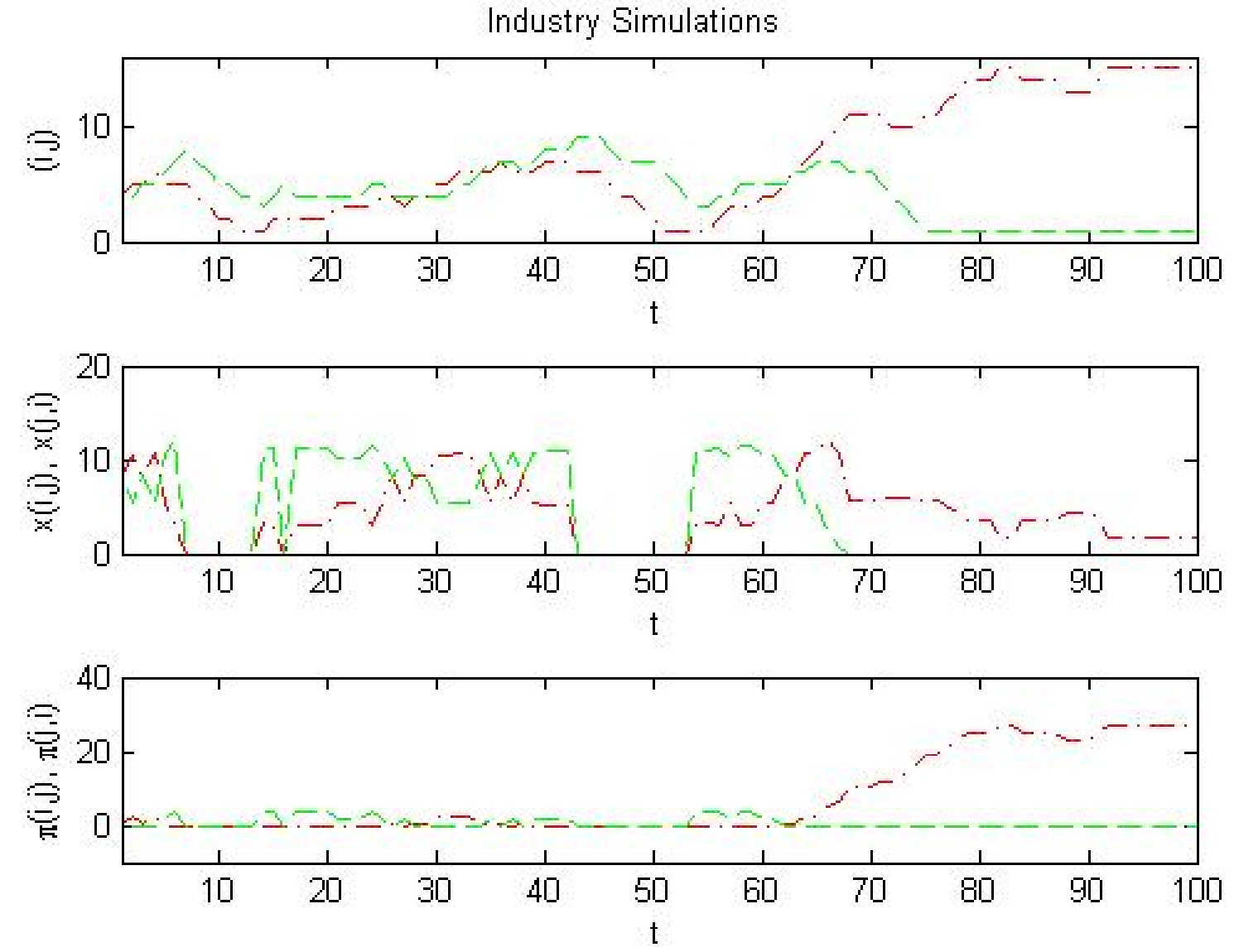

Figure 7: Industry Simulations $-\delta=0.4, c=0.8, \omega=0.5$ 

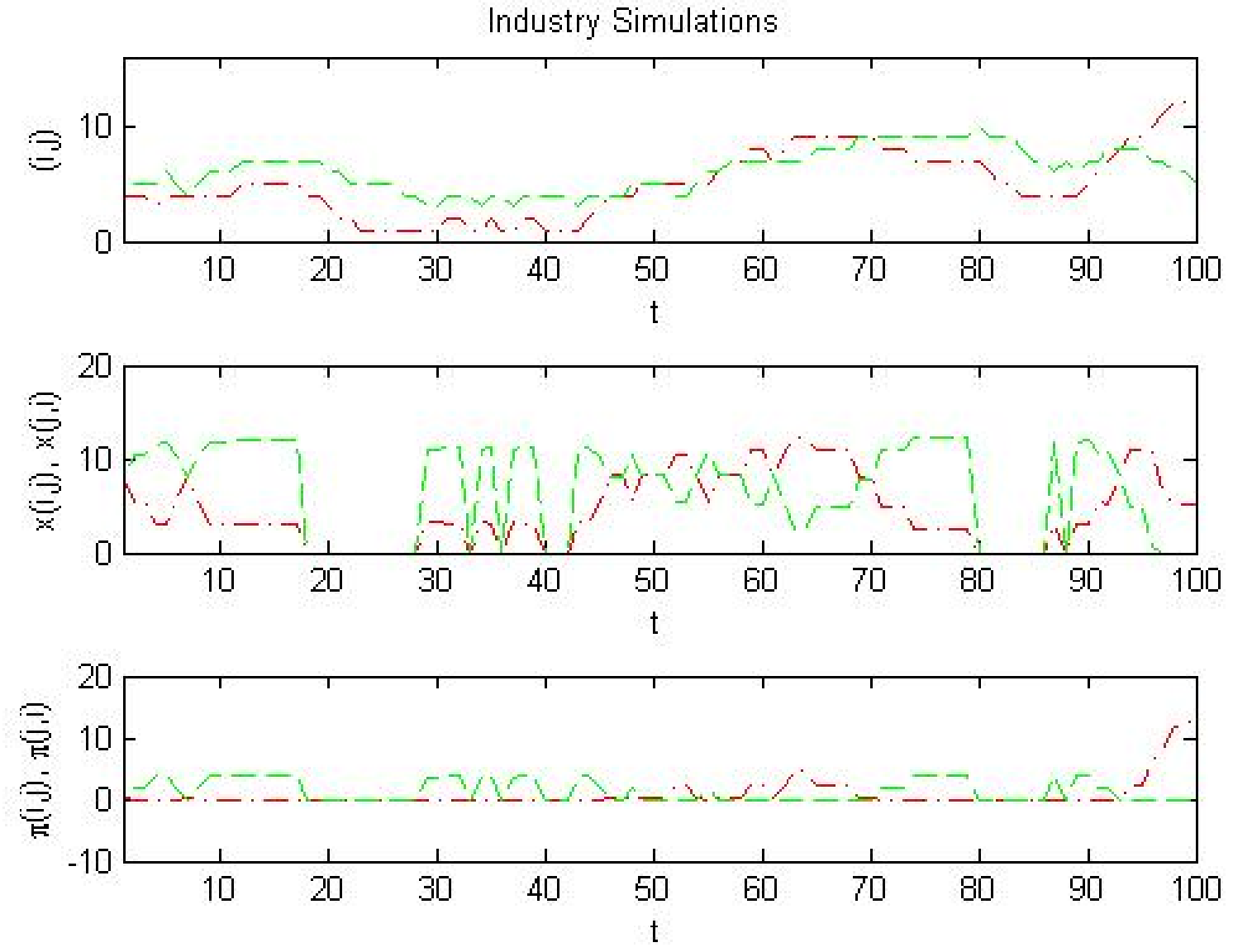

Figure 8: Industry Simulations $-\delta=0.8, c=0.4, \omega=0.5$ 
Table 1: Industry Performance - Social Planner

\begin{tabular}{cccc}
\hline \hline & & & \\
& $\omega=0.4$ & $\omega=0.8$ & $\omega=0.8$ \\
\hline$\delta=0.4$ & & & \\
$\mathrm{E}(\pi(i, j, f))$ & 4.44 & 3.01 & 5.20 \\
$\mathrm{E}(x(i, j, f))$ & 0.76 & 0.55 & 0.63 \\
Inefficiency on $x$ & 0.31 & 0.25 & 0.38 \\
\hline & & & \\
$\delta=0.7$ & & & \\
$\mathrm{E}(\pi(i, j, f))$ & 1.66 & 1.75 & 3.76 \\
$\mathrm{E}(x(i, j, f))$ & 0.53 & 0.38 & 0.46 \\
Inefficiency on $x$ & 0.08 & 0.13 & 0.43
\end{tabular}

Notes: The table shows the mean of each variable observed for each quality state. Values are weighted using the limiting (long-run) distribution of the associated markov process.

Table 2: R\&D Intensity (R\&D Expenditures / Sales)

\begin{tabular}{|c|c|c|c|c|c|c|c|c|}
\hline & \multicolumn{4}{|c|}{ Short-run $T=5$} & \multicolumn{4}{|c|}{ Long-run $T=\infty$} \\
\hline & $\omega=0.2$ & 0.4 & 0.6 & 0.8 & $\omega=0.2$ & 0.4 & 0.6 & 0.8 \\
\hline$\delta=0.2$ & 1.190 & 1.078 & 0.987 & 0.912 & 0.016 & 0.017 & 0.018 & 0.019 \\
\hline$\delta=0.4$ & 1.227 & 1.133 & 1.056 & 0.990 & 0.033 & 0.034 & 0.080 & 0.035 \\
\hline$\delta=0.6$ & 1.122 & 1.045 & 0.980 & 0.924 & 0.058 & 0.058 & 0.057 & 0.057 \\
\hline$\delta=0.8$ & 0.804 & 0.634 & 0.728 & 0.697 & 0.117 & 0.115 & 0.113 & 0.111 \\
\hline
\end{tabular}

Notes: The table shows the mean of the R\&D intensity observed in each quality state. Values are weighted using the limiting (long-run) distribution of the associated markov process. 
Table 3: Simulations of Industry Evolution - Short-run $(T=5)$

\begin{tabular}{|c|c|c|c|c|c|c|c|c|}
\hline \multirow{2}{*}{$\begin{array}{l}\text { Variable: } \\
\delta \downarrow, \omega \rightarrow\end{array}$} & \multicolumn{4}{|c|}{ Incumbent Firm (at $t=0)$} & \multicolumn{4}{|c|}{ Entrant Firm (at $t=0)$} \\
\hline & 0.2 & 0.4 & 0.6 & 0.8 & 0.2 & 0.4 & 0.6 & 0.8 \\
\hline \multicolumn{9}{|c|}{ 1. R\&D Investments $(x)$ : } \\
\hline 0.2 & $\begin{array}{c}34.41 \\
(10.26)\end{array}$ & $\begin{array}{l}37.63 \\
(8.97)\end{array}$ & $\begin{array}{l}38.38 \\
(9.88)\end{array}$ & $\begin{array}{l}39.22 \\
(8.68)\end{array}$ & $\begin{array}{l}37.38 \\
(9.25)\end{array}$ & $\begin{array}{l}36.66 \\
(9.59)\end{array}$ & $\begin{array}{l}37.34 \\
(9.77)\end{array}$ & $\begin{array}{l}38.69 \\
(8.05)\end{array}$ \\
\hline 0.4 & $\begin{array}{l}34.04 \\
(7.20)\end{array}$ & $\begin{array}{c}33.77 \\
(8.03)\end{array}$ & $\begin{array}{c}35.34 \\
(8.38)\end{array}$ & $\begin{array}{c}34.55 \\
(8.03)\end{array}$ & $\begin{array}{l}32.73 \\
(8.13)\end{array}$ & $\begin{array}{c}34.49 \\
(8.06)\end{array}$ & $\begin{array}{c}33.54 \\
(8.93)\end{array}$ & $\begin{array}{l}36.37 \\
(7.30)\end{array}$ \\
\hline 0.6 & $\begin{array}{c}30.65 \\
(7.29)\end{array}$ & $\begin{array}{l}30.90 \\
(7.54)\end{array}$ & $\begin{array}{c}31.64 \\
(7.53)\end{array}$ & $\begin{array}{l}32.54 \\
(7.55)\end{array}$ & $\begin{array}{l}29.24 \\
(7.64)\end{array}$ & $\begin{array}{l}30.44 \\
(7.52)\end{array}$ & $\begin{array}{l}30.74 \\
(7.98)\end{array}$ & $\begin{array}{l}31.82 \\
(7.42)\end{array}$ \\
\hline 0.8 & $\begin{array}{l}24.04 \\
(6.87)\end{array}$ & $\begin{array}{l}24.95 \\
(8.14)\end{array}$ & $\begin{array}{c}24.93 \\
(8.33)\end{array}$ & $\begin{array}{c}26.63 \\
(7.91)\end{array}$ & $\begin{array}{l}22.04 \\
(7.22)\end{array}$ & $\begin{array}{l}22.62 \\
(7.81)\end{array}$ & $\begin{array}{l}24.62 \\
(8.36)\end{array}$ & $\begin{array}{l}25.52 \\
(8.32)\end{array}$ \\
\hline \multicolumn{9}{|c|}{ 2. Cash Flows $(\pi-c x)$ : } \\
\hline 0.2 & $\begin{array}{l}-7.06 \\
(3.04)\end{array}$ & $\begin{array}{l}-6.55 \\
(3.98)\end{array}$ & $\begin{array}{c}-5.66 \\
(4.15)\end{array}$ & $\begin{array}{l}-5.80 \\
(3.57)\end{array}$ & $\begin{array}{l}-6.73 \\
(4.25)\end{array}$ & $\begin{array}{l}-7.59 \\
(4.00)\end{array}$ & $\begin{array}{l}-6.85 \\
(4.71)\end{array}$ & $\begin{array}{c}-7.16 \\
(4.60)\end{array}$ \\
\hline 0.4 & $\begin{array}{l}-5.70 \\
(4.30)\end{array}$ & $\begin{array}{l}-5.26 \\
(3.78)\end{array}$ & $\begin{array}{c}-3.55 \\
(4.91)\end{array}$ & $\begin{array}{c}-4.53 \\
(4.23)\end{array}$ & $\begin{array}{l}-6.67 \\
(3.28)\end{array}$ & $\begin{array}{l}-5.67 \\
(3.70)\end{array}$ & $\begin{array}{l}-5.16 \\
(4.37)\end{array}$ & $\begin{array}{l}-4.97 \\
(5.65)\end{array}$ \\
\hline 0.6 & $\begin{array}{l}-4.36 \\
(4.14)\end{array}$ & $\begin{array}{l}-3.99 \\
(3.99)\end{array}$ & $\begin{array}{c}-2.81 \\
(5.32)\end{array}$ & $\begin{array}{c}-2.65 \\
(4.87)\end{array}$ & $\begin{array}{l}-5.19 \\
(3.58)\end{array}$ & $\begin{array}{l}-4.73 \\
(4.28)\end{array}$ & $\begin{array}{l}-4.25 \\
(4.86)\end{array}$ & $\begin{array}{l}-4.15 \\
(5.30)\end{array}$ \\
\hline 0.8 & $\begin{array}{l}-2.95 \\
(3.80)\end{array}$ & $\begin{array}{l}-1.63 \\
(3.71)\end{array}$ & $\begin{array}{l}-1.11 \\
(5.41)\end{array}$ & $\begin{array}{c}-0.58 \\
(5.50)\end{array}$ & $\begin{array}{l}-3.87 \\
(2.75)\end{array}$ & $\begin{array}{l}-2.72 \\
(3.79)\end{array}$ & $\begin{array}{l}-1.96 \\
(5.56)\end{array}$ & $\begin{array}{l}-1.97 \\
(5.49)\end{array}$ \\
\hline
\end{tabular}

Notes: The table shows means and standard deviations (in parenthesis). Each calculation is based on 100 simulation runs. The parameter values are specified in the table, using $c=0.3$ and $\beta=0.925$. At $t=0$ both firms are symmetric in quality with $a_{i}=a_{j}=3$. 
Table 4: Simulations of Industry Evolution - Medium-run $(T=25)$

\begin{tabular}{|c|c|c|c|c|c|c|c|c|}
\hline \multirow{2}{*}{$\begin{array}{l}\text { Variable: } \\
\delta \downarrow, \omega \rightarrow\end{array}$} & \multicolumn{4}{|c|}{ Incumbent Firm (at $t=0)$} & \multicolumn{4}{|c|}{ Entrant Firm (at $t=0)$} \\
\hline & 0.2 & 0.4 & 0.6 & 0.8 & 0.2 & 0.4 & 0.6 & 0.8 \\
\hline \multicolumn{9}{|c|}{ 1. R\&D Investments $(x)$ : } \\
\hline 0.2 & $\begin{array}{c}55.83 \\
(24.40)\end{array}$ & $\begin{array}{c}66.99 \\
(23.73)\end{array}$ & $\begin{array}{c}63.95 \\
(24.61)\end{array}$ & $\begin{array}{c}65.73 \\
(23.48)\end{array}$ & $\begin{array}{c}64.13 \\
(24.34)\end{array}$ & $\begin{array}{c}61.41 \\
(24.16)\end{array}$ & $\begin{array}{c}63.37 \\
(24.83)\end{array}$ & $\begin{array}{c}65.79 \\
(23.89)\end{array}$ \\
\hline 0.4 & $\begin{array}{c}71.35 \\
(26.07)\end{array}$ & $\begin{array}{c}65.47 \\
(28.28)\end{array}$ & $\begin{array}{c}70.99 \\
(27.63)\end{array}$ & $\begin{array}{c}65.48 \\
(28.68)\end{array}$ & $\begin{array}{c}63.82 \\
(26.38)\end{array}$ & $\begin{array}{c}71.69 \\
(26.92)\end{array}$ & $\begin{array}{c}66.39 \\
(29.15)\end{array}$ & $\begin{array}{c}73.99 \\
(26.29)\end{array}$ \\
\hline 0.6 & $\begin{array}{c}70.36 \\
(27.56)\end{array}$ & $\begin{array}{c}68.74 \\
(29.46)\end{array}$ & $\begin{array}{l}73.76 \\
(28.35)\end{array}$ & $\begin{array}{l}75.34 \\
(29.70)\end{array}$ & $\begin{array}{c}66.21 \\
(29.49)\end{array}$ & $\begin{array}{l}69.70 \\
(29.97)\end{array}$ & $\begin{array}{c}67.16 \\
(32.16)\end{array}$ & $\begin{array}{c}70.23 \\
(29.13)\end{array}$ \\
\hline 0.8 & $\begin{array}{c}58.59 \\
(28.09)\end{array}$ & $\begin{array}{c}60.94 \\
(30.48)\end{array}$ & $\begin{array}{c}56.42 \\
(31.41)\end{array}$ & $\begin{array}{c}64.10 \\
(29.18)\end{array}$ & $\begin{array}{c}52.55 \\
(28.98)\end{array}$ & $\begin{array}{c}52.92 \\
(29.67)\end{array}$ & $\begin{array}{c}60.93 \\
(30.85)\end{array}$ & $\begin{array}{c}58.67 \\
(30.47)\end{array}$ \\
\hline \multicolumn{9}{|c|}{ 2. Cash Flows $(\pi-c x)$ : } \\
\hline 0.2 & $\begin{array}{c}18.11 \\
(45.06)\end{array}$ & $\begin{array}{c}23.81 \\
(43.81)\end{array}$ & $\begin{array}{l}24.79 \\
(48.91)\end{array}$ & $\begin{array}{c}25.98 \\
(45.40)\end{array}$ & $\begin{array}{c}29.63 \\
(50.03)\end{array}$ & $\begin{array}{c}13.43 \\
(41.34)\end{array}$ & $\begin{array}{l}23.78 \\
(46.95)\end{array}$ & $\begin{array}{c}22.65 \\
(44.66)\end{array}$ \\
\hline 0.4 & $\begin{array}{c}22.87 \\
(44.59)\end{array}$ & $\begin{array}{l}15.80 \\
(38.74)\end{array}$ & $\begin{array}{l}27.50 \\
(46.98)\end{array}$ & $\begin{array}{c}18.54 \\
(44.40)\end{array}$ & $\begin{array}{c}12.82 \\
(40.27)\end{array}$ & $\begin{array}{c}26.05 \\
(44.55)\end{array}$ & $\begin{array}{l}21.90 \\
(43.74)\end{array}$ & $\begin{array}{c}33.15 \\
(50.28)\end{array}$ \\
\hline 0.6 & $\begin{array}{c}17.27 \\
(39.23)\end{array}$ & $\begin{array}{c}16.28 \\
(37.22)\end{array}$ & $\begin{array}{l}22.40 \\
(39.87)\end{array}$ & $\begin{array}{c}21.92 \\
(38.65)\end{array}$ & $\begin{array}{c}10.56 \\
(32.80)\end{array}$ & $\begin{array}{c}15.24 \\
(36.21)\end{array}$ & $\begin{array}{l}13.22 \\
(36.04)\end{array}$ & $\begin{array}{c}14.81 \\
(38.12)\end{array}$ \\
\hline 0.8 & $\begin{array}{c}8.60 \\
(21.09)\end{array}$ & $\begin{array}{l}10.58 \\
(20.08)\end{array}$ & $\begin{array}{l}13.10 \\
(27.38)\end{array}$ & $\begin{array}{l}15.85 \\
(26.79)\end{array}$ & $\begin{array}{c}7.93 \\
(17.59)\end{array}$ & $\begin{array}{c}7.80 \\
(22.89)\end{array}$ & $\begin{array}{c}14.47 \\
(26.48)\end{array}$ & $\begin{array}{l}10.49 \\
(25.00)\end{array}$ \\
\hline
\end{tabular}

Notes: The table shows means and standard deviations (in parenthesis). Each calculation is based on 100 simulation runs. The parameter values are specified in the table, using $c=0.3$ and $\beta=0.925$. At $t=0$ both firms are symmetric in quality with $a_{i}=a_{j}=3$. 
Table 5: Simulations of Industry Evolution - Long-run $(T=100)$

\begin{tabular}{|c|c|c|c|c|c|c|c|c|}
\hline \multirow{2}{*}{$\begin{array}{l}\text { Variable: } \\
\delta \downarrow, \omega \rightarrow\end{array}$} & \multicolumn{4}{|c|}{ Incumbent Firm (at $t=0)$} & \multicolumn{4}{|c|}{ Entrant Firm (at $t=0)$} \\
\hline & 0.2 & 0.4 & 0.6 & 0.8 & 0.2 & 0.4 & 0.6 & 0.8 \\
\hline \multicolumn{9}{|c|}{ 1. R\&D Investments $(x)$ : } \\
\hline 0.2 & $\begin{array}{c}56.77 \\
(25.16)\end{array}$ & $\begin{array}{c}68.51 \\
(24.59)\end{array}$ & $\begin{array}{c}65.33 \\
(25.56)\end{array}$ & $\begin{array}{c}67.34 \\
(24.52)\end{array}$ & $\begin{array}{c}65.29 \\
(25.05)\end{array}$ & $\begin{array}{c}62.41 \\
(24.90)\end{array}$ & $\begin{array}{c}64.68 \\
(25.74)\end{array}$ & $\begin{array}{c}67.06 \\
(24.81)\end{array}$ \\
\hline 0.4 & $\begin{array}{c}73.82 \\
(27.69)\end{array}$ & $\begin{array}{c}67.66 \\
(30.10)\end{array}$ & $\begin{array}{c}73.37 \\
(29.44)\end{array}$ & $\begin{array}{c}67.58 \\
(30.46)\end{array}$ & $\begin{array}{c}65.77 \\
(28.07)\end{array}$ & $\begin{array}{c}74.40 \\
(28.73)\end{array}$ & $\begin{array}{c}68.95 \\
(31.14)\end{array}$ & $\begin{array}{r}77.00 \\
(28.14)\end{array}$ \\
\hline 0.6 & $\begin{array}{c}75.38 \\
(30.99)\end{array}$ & $\begin{array}{c}73.39 \\
(33.23)\end{array}$ & $\begin{array}{c}78.90 \\
(32.01)\end{array}$ & $\begin{array}{c}80.69 \\
(33.52)\end{array}$ & $\begin{array}{c}71.16 \\
(33.36)\end{array}$ & $\begin{array}{c}74.95 \\
(33.93)\end{array}$ & $\begin{array}{c}71.97 \\
(36.29)\end{array}$ & $\begin{array}{c}74.68 \\
(33.07)\end{array}$ \\
\hline 0.8 & $\begin{array}{c}66.83 \\
(34.37)\end{array}$ & $\begin{array}{c}68.82 \\
(36.15)\end{array}$ & $\begin{array}{c}63.93 \\
(37.60)\end{array}$ & $\begin{array}{c}72.27 \\
(34.90)\end{array}$ & $\begin{array}{c}59.51 \\
(35.08)\end{array}$ & $\begin{array}{c}60.63 \\
(35.11)\end{array}$ & $\begin{array}{c}68.98 \\
(36.80)\end{array}$ & $\begin{array}{c}66.32 \\
(36.07)\end{array}$ \\
\hline \multicolumn{9}{|c|}{ 2. Cash Flows $(\pi-c x)$ : } \\
\hline 0.2 & $\begin{array}{c}33.42 \\
(65.65)\end{array}$ & $\begin{array}{c}44.17 \\
(63.69)\end{array}$ & $\begin{array}{c}41.99 \\
(70.77)\end{array}$ & $\begin{array}{c}44.73 \\
(67.41)\end{array}$ & $\begin{array}{c}51.20 \\
(71.20)\end{array}$ & $\begin{array}{c}27.26 \\
(61.01)\end{array}$ & $\begin{array}{c}42.19 \\
(68.73)\end{array}$ & $\begin{array}{c}40.32 \\
(66.53)\end{array}$ \\
\hline 0.4 & $\begin{array}{c}46.08 \\
(64.60)\end{array}$ & $\begin{array}{c}34.26 \\
(58.95)\end{array}$ & $\begin{array}{c}48.67 \\
(69.07)\end{array}$ & $\begin{array}{c}34.73 \\
(65.51)\end{array}$ & $\begin{array}{c}30.24 \\
(60.04)\end{array}$ & $\begin{array}{c}49.63 \\
(65.58)\end{array}$ & $\begin{array}{c}44.17 \\
(64.41)\end{array}$ & $\begin{array}{r}59.37 \\
(71.58)\end{array}$ \\
\hline 0.6 & $\begin{array}{c}36.52 \\
(56.90)\end{array}$ & $\begin{array}{c}34.70 \\
(54.36)\end{array}$ & $\begin{array}{c}42.95 \\
(58.71)\end{array}$ & $\begin{array}{c}44.39 \\
(57.24)\end{array}$ & $\begin{array}{c}27.73 \\
(48.84)\end{array}$ & $\begin{array}{c}34.39 \\
(53.06)\end{array}$ & $\begin{array}{c}31.30 \\
(53.64)\end{array}$ & $\begin{array}{c}32.85 \\
(56.73)\end{array}$ \\
\hline 0.8 & $\begin{array}{c}18.04 \\
(29.75)\end{array}$ & $\begin{array}{c}18.65 \\
(28.20)\end{array}$ & $\begin{array}{c}22.36 \\
(37.30)\end{array}$ & $\begin{array}{c}26.13 \\
(36.97)\end{array}$ & $\begin{array}{c}12.58 \\
(26.34)\end{array}$ & $\begin{array}{c}16.77 \\
(32.52)\end{array}$ & $\begin{array}{c}24.75 \\
(36.49)\end{array}$ & $\begin{array}{c}19.51 \\
(34.33)\end{array}$ \\
\hline
\end{tabular}

Notes: The table shows means and standard deviations (in parenthesis). Each calculation is based on 100 simulation runs. The parameter values are specified in the table, using $c=0.3$ and $\beta=0.925$. At $t=0$ both firms are symmetric in quality with $a_{i}=a_{j}=3$. 